\title{
Statistical Data Analyses on Aircraft Accidents in Japan: Occurrences, Causes and Countermeasures
}

\author{
Kunimitsu Iwadare, Tatsuo Oyama \\ National Graduate Institute for Policy Studies (GRIPS) 7-22-1 Roppongi Minato-ku, Tokyo, Japan \\ Email: oyamat@grips.ac.jp
}

Received 28 March 2015; accepted 25 May 2015; published 28 May 2015

Copyright (C) 2015 by authors and Scientific Research Publishing Inc.

This work is licensed under the Creative Commons Attribution International License (CC BY). http://creativecommons.org/licenses/by/4.0/

c) (7) Open Access

\section{Abstract}

We investigate the major characteristics of the occurrences, causes of and counter measures for aircraft accidents in Japan. We apply statistical data analysis and mathematical modeling techniques to determine the relations among economic growth, aviation demand, the frequency of aircraft/helicopter accidents, the major characteristics of the occurrence intervals of accidents, and the number of fatalities due to accidents. The statistical model analysis suggests that the occurrence intervals of accidents and the number of fatalities can be explained by probability distributions such as the exponential distribution and the negative binomial distribution, respectively. We show that countermeasures for preventing accidents have been developed in every aircraft model, and thus they have contributed to a significant decrease in the number of accidents in the last three decades. We find that the major cause of accidents involving large airplanes has been weather, while accidents involving small airplanes and helicopters are mainly due to the pilot error. We also discover that, with respect to accidents mainly due to pilot error, there is a significant decrease in the number of accidents due to the aging of airplanes, whereas the number of accidents due to weather has barely declined. We further determine that accidents involving small and large airplanes mostly occur during takeoff and landing, whereas those involving helicopters are most likely to happen during flight. In order to decrease the number of accidents, i) enhancing safety and security by further developing technologies for aircraft, airports and air control radars, ii) establishing and improving training methods for crew including pilots, mechanics and traffic controllers, iii) tightening public rules, and iv) strengthening efforts made by individual aviation-related companies are absolutely necessary.

\section{Keywords}

\section{Statistical Data Analysis, Aircraft Accidents, Causes of Aircraft Accidents, Accident-Prevention}

How to cite this paper: Iwadare, K. and Oyama, T. (2015) Statistical Data Analyses on Aircraft Accidents in Japan: Occurrences, Causes and Countermeasures. American Journal of Operations Research, 5, 222-245. 


\section{Introduction}

Plane crashes, excluding those related to the Self-Defence Forces, have occurred more than 10 times a year on average during the period from 1974 to 2010 in Japan. With the growth of the economy, e.g. gross domestic product (GDP), aircrafts have been becoming a more common andpopular means of transportation for ordinary citizens. Now, most people's international travel is conducted by airplane. Although the demand growth for aircraft has been very high, the number of airplane accidents has been decreasing over the last 30 to 50 years. Airplane accidents have been efficiently prevented by modern technological innovations. In this paper, we aim to investigatethe major characteristics of the occurrences and causes of and countermeasures for aircraft accidents in Japan. We apply statistical data analysis and mathematical modeling techniques to determine the relationships among economic growth, aviation demand, the frequency of aircraft/helicopter accidents, the intervals of accidents, and the number of fatalities.

Regarding aircraft accident studies, Bazargan and Vitaly [1] investigated the data obtained from 40,000 accidents that occurred in the United States between 1983 and 2002 in order to determine the level of influence on the accidents of various factors such as the gender, age and length of experience of pilots who had been involved in accidents. They concluded that inexperienced pilots had a high probability of causing accidents due to various types of human errors. Chang and Yang [2] classified survival factors for in-flight safety into the following categories: design and equipment of the aircraft, education for pilots and crew and cooperation among them, passengers' behavior and safety education for them, and the ability to cope with emergencies. They selected 47 items from these categories and ranked them in terms of the level of importance. Based on their ranking, they stated that proper instructions by pilots and crew in case of emergency and evacuation and training for managing a crowd of people were of particular importance.

In Japan, Rinoie [3] reported various efforts made for the future, discussing the methods of ensuring safety from an operational viewpoint, which included the improvement of cockpit functions, the development of a system that would enable safe and solid flight operation, and also reforms to the pilot licensing system. Shiroyama et al. [4] discussed establishing an aircraft accident investigation system adopted in the United States, introducing a research method based on the collection of experts' knowledge, support for victims and their families from third-party organizations, and procedures for pursuing legal responsibility. Shiroyama et al. [4] emphasized that Japan should review the existing situation in terms of adequate manpower, the establishment of an investigation framework and proper treatment of bereaved families. Nakasuga [5] suggested the need for psychologial training and fail-safes in order to cope with "panic" from the aspect of human factors, explaining the relationship between aircraft and people in the process of automation in light of aspects of human nature such as miscommunication and habituation. Kamiyama [6] investigated carefully various types of safety measures based on data of plane crashes he statistically compiled. As far as we know, there is scant literature where plane accident data have been statistically analyzed.

This paper aimed to investigate the historical trend and transitional characteristics of aircraft accidents in Japan to determine the properties and characteristics related with their occurrences and causes, identify how accident-prevention policies and measures were taken in addition to indicating that the accident data regarding the occurrence of accidents and the number of fatalities were in accordance with various mathematical models. Based on the results of these attempts, we try to forecast for the future and discuss safety and related measures in order to contribute to air traffic safety. There have been various studies on aircraft accidents at home and abroad as mentioned above, most of which have focused on contributing factors in a particular accident and have analyzed measures to deal with them in detail. Our paper aims to look at aircraft accidents from a panoramic viewpoint in terms of descriptive statistics. We believe that there are very few arguments over what the priority of an effective measure will be when we are required to deal with a certain accident. Also, we try to evaluate whether past measures are appropriate or not. In Japan, the Japan Transport Safety Board, a branch of the Ministry of Land, Infrastructure, Transport and Tourism (MLIT), publishes comprehensive information regarding accident data. By investigating the highly reliable accident data, this paper aims to contribute to the formulation of effective measures against aircraft accidents in Japan. 
In the next chapter, we utilize aircraft accident data regarding Japan's major means of air transportation such as small and large airplanes and helicopters over the past 37 years. We analyze accidents due to the aging of airplanes, changes in the number of fatalities, causes of the accidents, and other factors. In Chapter 3 , we identify the history of the accidents and measures to prevent them as well as the characteristics of their trends in terms of accident factors. In Chapter 4, we build mathematical models by investigating the economic growth, aviation demand, the relationship between the aviation demand and the accident figures, the occurrence intervals of accidents, and the number of fatalities during a certain period of time. Finally, in the Summary and Conclusions we discuss the major findings, and highlight the necessary issues that should be included in countermeasures for preventing accidents for small and large airplanes and helicopters.

\section{Aircraft Accidents in Japan}

\subsection{Airplane and Helicopter Accidents}

In Article 76, Paragraph 1 of the Civil Aeronautics Act established in 1952, aircraft accidents are defined as follows: i) crash, collision and fire on an aircraft, ii) casualties and damage to properties due to the aircraft accident, iii) missing and dead among those who were inside the aircraft, iv) minor collision with other aircraft, and v) other aircraft-related accidents specified in the ministerial ordinance of the MLIT. Government regulations require the reporting of the above accidents. The so-called aircraft as a means of transportation range from small airplanes accommodating a few passengers to large craft that are able to carry hundreds of people. There are also helicopters that fly on various missions, including lifesaving, news gathering activities, observation and monitoring. In this study, when analyzing accidents involving airplanes and helicopters, we classify aircraft weighing more than $5700 \mathrm{~kg}$ as large airplanes, and those weighing less than $5700 \mathrm{~kg}$ as small airplanes. In our data analysis, we use accident data made publicly available by the Japan Transport Safety Board on their website [7].

Table 1 shows the numbers of airplane and helicopter landings and accidents with small airplanes figure and their respective fatalities from 1974 to 2010 in parentheses. Thus the number of large airplane accidents and fatalities can be calculated by deducting the data in parentheses from the corresponding total in Table 1. Missing data in Table 1 are not available. The number of small airplane accidents marked a record high of 28 in 1976 while the lowest is 2 in 2006 and 2009. The coefficient of variation is 0.54 for small airplanes accidents data. The highest number of fatalities was 17 in 1986, whereas there were none in 1993, 1999, 2006 and 2009. The coefficient of variation is 0.87 for fatalities data.

Regarding the number of accidents involving large airplanes, the highest is 7 in 1976, and the lowest is 0 in 2010. The coefficient of variation is 0.51 , smaller than the above small airplanes case. The number of fatalities in 1985 is 520 people, the highest on record. The number of years that there are no fatalities is 22 . The coefficient of variation is 4.22, the largest among all types of aircraft accidents data. In terms of aircraft in general, the highest number of accidents is 35 in 1976 while the lowest is 5 in 2006 and 2009. The coefficient of variation is 0.47 .

Figure 1 is a piecewise linear graph showing the number of such accidents as well as the number of aircraft landings. From 1974 to 2010, the total number of accidents involving small airplanes was 351, which accounts for $75.1 \%$ of the total number of 467 aircraft accidents for the entire period. Figure 2 shows the changes over the period in the number of helicopter accidents as well as the number of landings. The highest number of accidents is 24 in 1978, whereas years 2003 and 2006 both marked 1, the lowest. The coefficient of variation is as small as 0.50 . The number of fatalities marked a record high of 31 in 1990, whereas it was 0 in 1995,1999 and 2006. The coefficient of variation is 1.03 , indicating a considerable variation.

\section{1) Landings and accidents of airplanes/helicopters}

Figure 1 indicates that, for the last 37 years, the growth in aviation demand in Japan shows an increase in the number of landings of about 15,000 annually. On the other hand, the number of accidents decreases by about 0.39 annually. Figure 2 suggests that the number of landings and accidents involving helicopters has gradually decreased over the last 20 to 30 years. As for helicopters, the number of landings decreases annually by about 435 , and the annual accident figure decreases by about 0.36 . The relationship between the aviation demand and accident figures will be discussed in Section 4.1.

The number of accidents per 100,000 landings per year varies.However, they are generally on the decrease, dropping to 0.5 in 2006 after peaking at 6.7 in 1976. Helicopter figures have also been decreasing after peaking 
Table 1. Number of airplane and helicopter landings, accidents and fatalities.

\begin{tabular}{|c|c|c|c|c|c|c|c|c|}
\hline \multirow{3}{*}{$\begin{array}{l}\text { Year } \\
1974\end{array}$} & \multicolumn{5}{|c|}{ Airplane } & \multicolumn{3}{|c|}{ Helicopter } \\
\hline & \multirow{2}{*}{$\begin{array}{c}\text { Landing }\left(10^{3} \text { times }\right) \\
536\end{array}$} & \multicolumn{2}{|c|}{ Number of accidents } & \multicolumn{2}{|c|}{ Number of fatalities } & \multirow[t]{2}{*}{$\begin{array}{c}\text { Landing } \\
\left(10^{3} \text { times }\right)\end{array}$} & \multirow{2}{*}{$\begin{array}{c}\text { Number of } \\
\text { accidents }\end{array}$} & \multirow{2}{*}{$\begin{array}{c}\begin{array}{c}\text { Number of } \\
\text { fatalities }\end{array} \\
6\end{array}$} \\
\hline & & 21 & $(16)$ & 3 & (2) & & & \\
\hline 1975 & 521 & 17 & $(15)$ & 5 & $(5)$ & & 15 & 1 \\
\hline 1976 & 521 & 35 & $(28)$ & 16 & (14) & & 17 & 5 \\
\hline 1977 & 551 & 14 & $(10)$ & 2 & (2) & & 12 & 3 \\
\hline 1978 & 579 & 15 & $(10)$ & 7 & $(6)$ & & 24 & 8 \\
\hline 1979 & 610 & 20 & $(15)$ & 5 & $(5)$ & & 16 & 1 \\
\hline 1980 & 610 & 15 & $(12)$ & 2 & (2) & & 23 & 2 \\
\hline 1981 & 622 & 15 & (11) & 33 & (7) & & 15 & 10 \\
\hline 1982 & 631 & 17 & (13) & 6 & (4) & & 11 & 5 \\
\hline 1983 & 629 & 14 & (13) & 10 & (9) & & 14 & 2 \\
\hline 1984 & 634 & 7 & (3) & 3 & (2) & & 10 & 4 \\
\hline 1985 & 637 & 15 & $(12)$ & 524 & (4) & & 18 & 6 \\
\hline 1986 & 653 & 19 & (14) & 17 & (17) & & 11 & 3 \\
\hline 1987 & 681 & 21 & (16) & 14 & (14) & & 8 & 3 \\
\hline 1988 & 704 & 7 & (5) & 7 & (6) & & 13 & 3 \\
\hline 1989 & 734 & 11 & (8) & 7 & (5) & & 11 & 7 \\
\hline 1990 & 747 & 13 & (12) & 5 & (5) & & 15 & 31 \\
\hline 1991 & 778 & 11 & (9) & 1 & (1) & 31 & 17 & 18 \\
\hline 1992 & 800 & 6 & (4) & 5 & (4) & 29 & 9 & 3 \\
\hline 1993 & 806 & 8 & (5) & 0 & $(0)$ & 27 & 16 & 2 \\
\hline 1994 & 856 & 9 & (6) & 266 & (2) & 29 & 15 & 6 \\
\hline 1995 & 896 & 8 & (6) & 5 & (4) & 26 & 4 & 0 \\
\hline 1996 & 925 & 18 & (12) & 12 & (7) & 26 & 10 & 13 \\
\hline 1997 & 949 & 14 & (11) & 7 & (7) & 26 & 6 & 8 \\
\hline 1998 & 982 & 16 & (14) & 15 & (15) & 25 & 5 & 2 \\
\hline 1999 & 982 & 9 & (7) & 0 & $(0)$ & 28 & 8 & 0 \\
\hline 2000 & 996 & 7 & (6) & 3 & (3) & 30 & 12 & 5 \\
\hline 2001 & 996 & 7 & (6) & 6 & (6) & 31 & 11 & 3 \\
\hline 2002 & 1020 & 8 & (5) & 5 & (5) & 27 & 11 & 4 \\
\hline 2003 & 1027 & 12 & (9) & 11 & (11) & 27 & 1 & 4 \\
\hline 2004 & 1043 & 13 & (11) & 3 & (3) & 28 & 6 & 5 \\
\hline 2005 & 1063 & 9 & (7) & 1 & (1) & 27 & 7 & 8 \\
\hline 2006 & 1097 & 5 & (2) & 0 & $(0)$ & 27 & 1 & 0 \\
\hline 2007 & 1100 & 9 & (3) & 2 & (2) & 27 & 7 & 6 \\
\hline 2008 & 1077 & 10 & (6) & 3 & (1) & 23 & 4 & 2 \\
\hline 2009 & 1060 & 5 & (2) & 0 & $(0)$ & 23 & 6 & 5 \\
\hline 2010 & 1060 & 7 & (7) & 4 & (4) & 23 & 4 & 14 \\
\hline Total & 30113 & 467 & (351) & 1015 & (185) & 538 & 410 & 208 \\
\hline Average & 813.9 & 12.6 & $(9.5)$ & 27.4 & $(5.0)$ & 26.9 & 11.1 & 5.6 \\
\hline $\begin{array}{l}\text { Standard } \\
\text { deviation }\end{array}$ & 197.8 & 6.0 & $(5.2)$ & 94.3 & $(4.4)$ & 2.4 & 5.6 & 5.8 \\
\hline Maximum & 1100 & 35 & (28) & 524 & (17) & 31 & 24 & 31 \\
\hline Minimum & 521 & 5 & (2) & 0 & (0) & 23 & 1 & 0 \\
\hline
\end{tabular}

Values in parentheses are the number of accidents and fatalities of small airplane. Source: The Japan Transport Safety Board [7], Aviation Statistics Catalogue, Japan Aeronautic Association, 1984-85, 1998-99, 2001, 2011 [8]. 


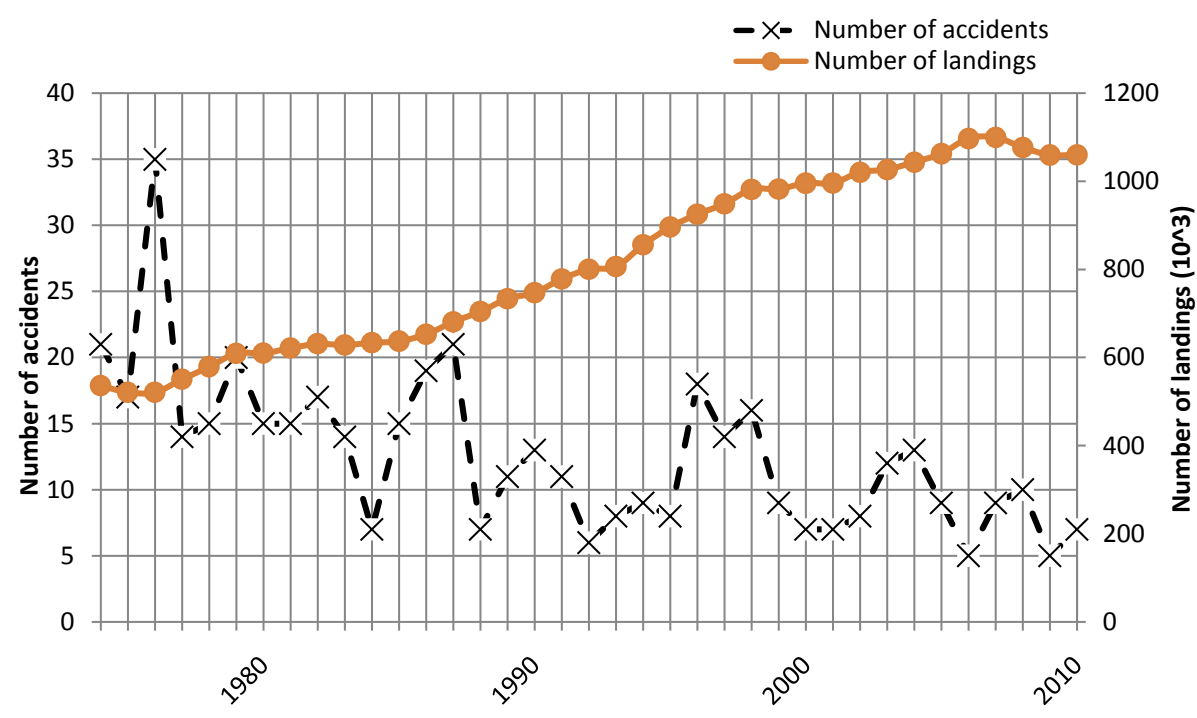

Figure 1. Landings and accidents for aircraft (1974-2010).

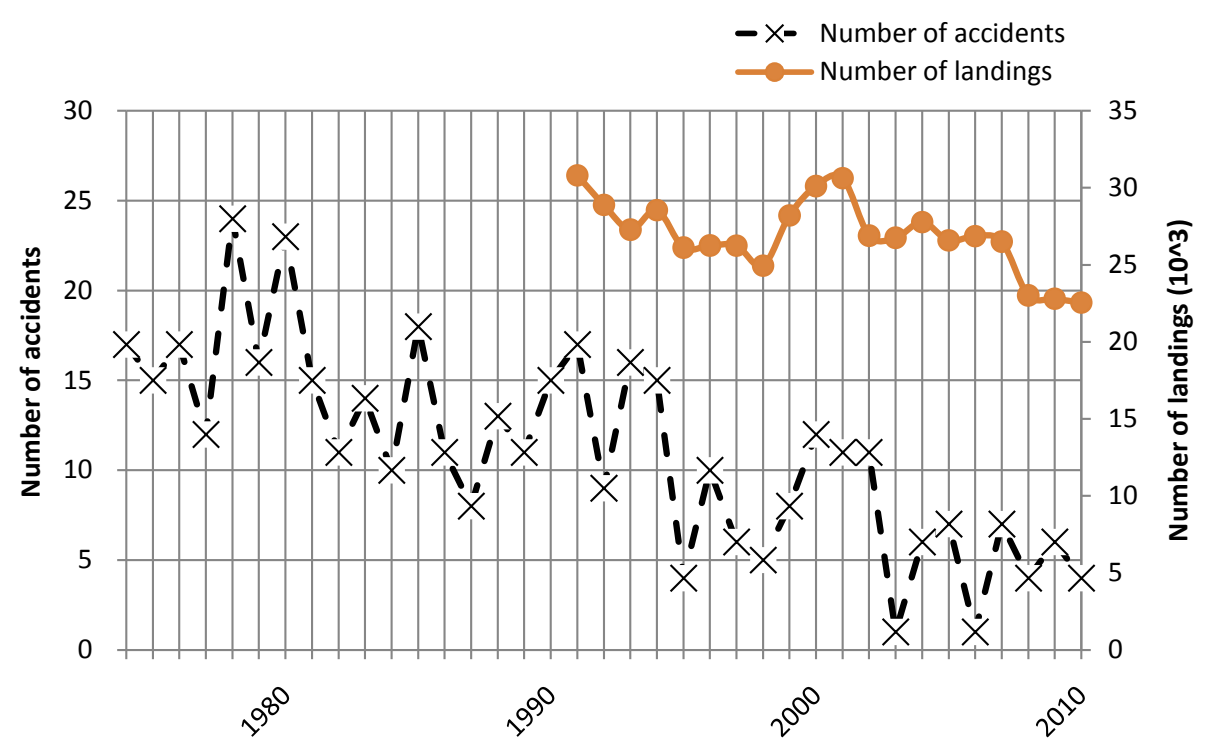

Figure 2. Landings and accidents for helicopter (1974-2010).

at 58.7 in 1993. As the number of landings is unavailable separately for both small and large airplanes, we could not make a simple comparison. However, as a means of air transportation, we can say there are numerous helicopter accidents. The accident figures vary with the season. For the entire period from 1974 to 2010, summer (June to August) has the highest accident figure of 191, followed by autumn (September to November) of 80, and 82 in spring (March to May). The lowest is 57 in winter (December to February). These seasonal trends are due to helicopter use. For comparison, we can see no particular seasonal variation in accidents of other types of aircraft. As described above, the number of helicopter accidents per landing is 16 times greater than for other types of aircraft. In order to reduce the number of accidents per landing, the first step is to implement preventive measures against helicopter accidents.

\section{2) Aircraft accidents by type}

Figure 3 shows the 3-year and 5-year moving average values respectively for large airplanes. The number of accidents for both small and large aircraft types has been decreasing every year. However, large airplanes display more variations and a smaller degree of decrease, compared to small airplanes. Furthermore, we can also see the possibility that the number of accidents increases or decreases about every 10 years. Especially, the crash 


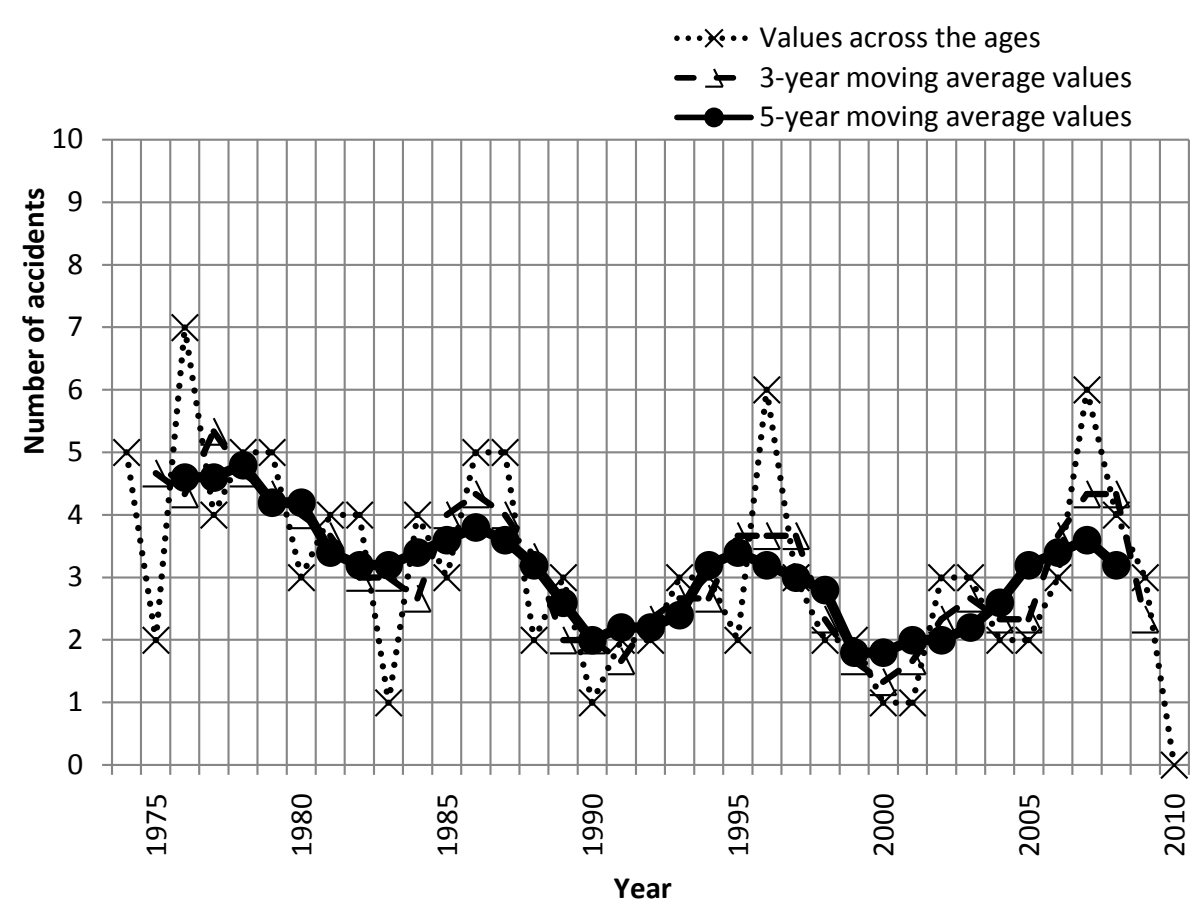

Figure 3. 3-year and 5-year moving averages for the number of accidents involving large airplanes (1974-2010).

of a JAL plane killing 520 people occurred in 1985, and the China Airlines accident killing 264 people happened in 1994. There were many other accidents around this period. In 2007, about 10 years after the China Airlines accident, the number of accidents was relatively high. Therefore, we can see that the number of accidents involving large airplanes increases approximately on a 10-year cycle.

\subsection{Fatalities Due to Airplane and Helicopter Accidents}

Regarding fatalities from aircraft accidents during the period from1974 to 2010, the highest was 524 people in 1985 whereas there was no fatalities in 1993, 1999, 2006 and 2009. It is still vivid in our memory that, on August 12, 1985, a Japan Airlines Jumbo Jet Flight 123 from Tokyo to Osaka crashed into a ridge near Mount Osutaka in Gunma Prefecture, taking the lives of 520 people. There is no doubt that this plane crash is the worst in Japan's avaiation history. However, also in the last 30 years, China Airlines Flight 140 crashed at Nagoya Airport, killing 264 people on board [7]. Such large airplane accidents become worse as the sizes of aircraft become larger, taking numerous lives once an accident occurs. This definitely has the potential of creating a serious social issue. Regarding helicopter accidents, the highest number of fatalities during our study period was 31 in 1990. There were no fatalities in 1995, 1999 and 2006. The high number of fatalities in 1990 is due to crashes involving large helicopters carrying 10 passengers and 6 passengers.

Calculating the standard deviation (SD) corresponding to the annual fatalities data during our study period, we found that those for small airplanes and helicopters were relatively low:4.4 and 5.8, respectively. On the other hand, the SD for large airplanes is as high as 94.6. Meanwhile, the SDs of accident figures for small airplanes and helicopters were 5.1 and 5.6, respectively. The SD of the number of large airplane accidents is relatively small at1.6. This means that the annual data of accident figures for large airplanes varies only a little; however, the number of fatalities is very likely to increase drastically once a large accident occurs.

Figure 4 and Figure 5 show the past trend of the number of fatalities from accidents involving small and large airplanes, and helicopters, respectively. Note that the JAL Jumbo Jet crash in 1985 and the China Airlines crash in 1994 are both excluded from the graph due to their enormous fatalities, 520 and 264, respectively. In Figure 4, the high number of fatalities in 1982 is due to an accident at Haneda Airport on February 9, killing 24 people. In Figure 5, the high number of fatalities in 1990 is due to crashes involving 2 helicopters having a large number of passengers, 10 and 6 , respectively. 


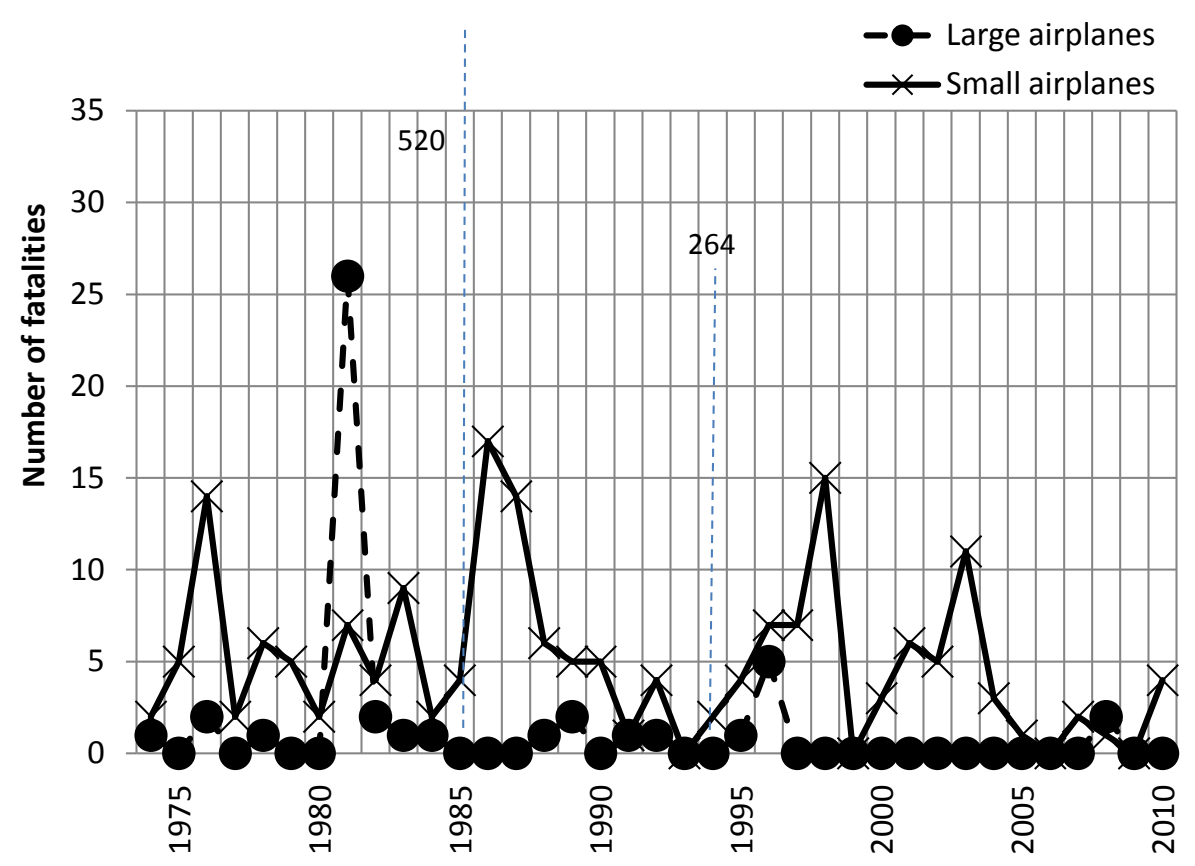

Figure 4. Fatalities from aircraft accidents (1974-2010).

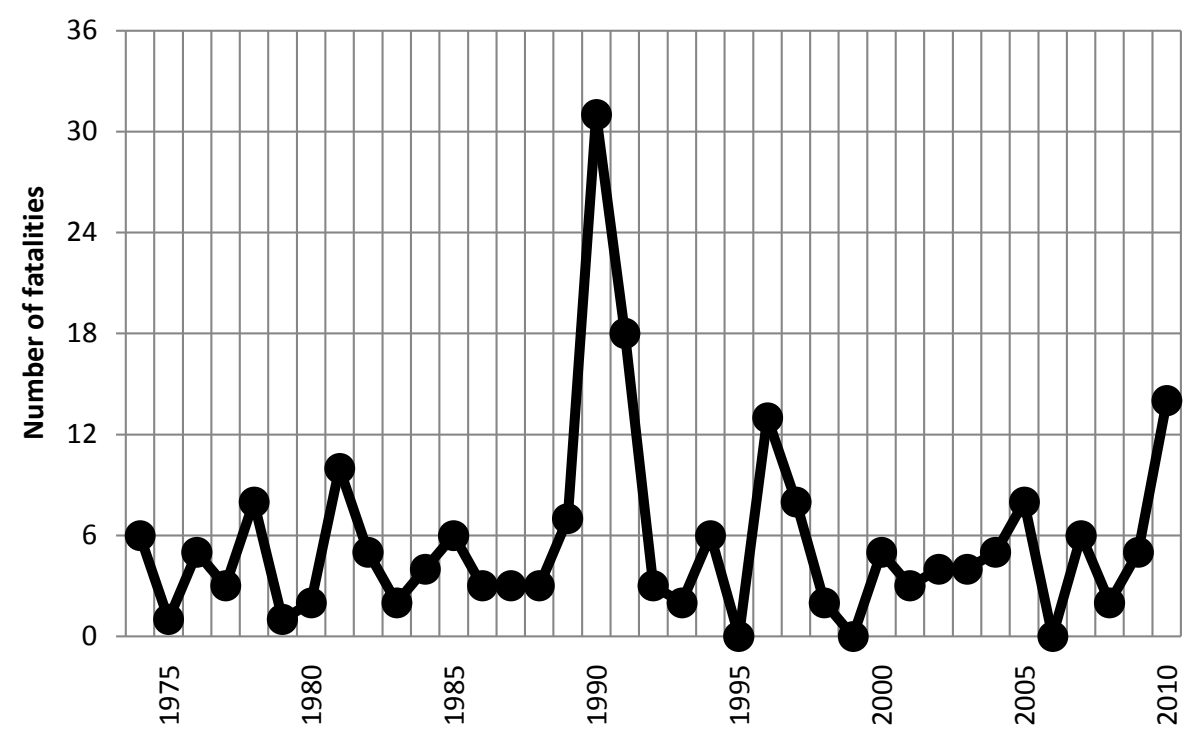

Figure 5. Numbers of fatalities from helicopter accidents (1974-2010).

Table 2 shows the number of fatalities from accidents for each period when we divide the entire study period between 1974 and 2010 into three periods: Period I: 1974-1985, Period II: 1986-1997, and Period III: 1998-2010. From Table 2, we can see that small airplanes and helicopters have a large number of fatalities in Period II. The increased number of fatalities in Period II, despite the fact that the number of accidents declined, is due to an increase in the number of accidents involving small airplanes and helicopters accommodating a relatively large number of passengers.

\section{Causes of Airplane/Helicopter Accidents and Accident-Prevention Measures}

\subsection{Causes of Airplane and Helicopter Accidents}

Using the data during the period from 1974 to 2007 in order to investigate the causes of airplane/helicopter ac- 
Table 2. Number of accidents and fatalities.

\begin{tabular}{ccccccccc}
\hline & \multicolumn{2}{c}{ Period } & \multicolumn{2}{c}{ Large airplanes } & \multicolumn{2}{c}{ Small airplanes } & \multicolumn{2}{c}{ Helicopters } \\
\hline \multirow{2}{*}{ I } & Accidents & 47 & $(3.9)$ & 158 & $(13.2)$ & 192 & $(16.0)$ \\
& Fatalities & 554 & $(46.2)$ & 62 & $(5.2)$ & 52 & $(4.3)$ \\
II & Accidents & 37 & $(3.1)$ & 108 & $(9.0)$ & 135 & $(11.3)$ \\
& Fatalities & 274 & $(22.8)$ & 72 & $(6.0)$ & 97 & $(8.1)$ \\
III & Accidents & 32 & $(2.5)$ & 85 & $(6.5)$ & 83 & $(6.4)$ \\
& Fatalities & 2 & $(0.2)$ & 51 & $(3.9)$ & 58 & $(4.5)$ \\
Total & Accidents & 116 & $(3.1)$ & 351 & $(9.5)$ & 410 & $(11.1)$ \\
& Fatalities & 830 & $(22.4)$ & 185 & $(5.0)$ & 207 & $(5.6)$ \\
\hline
\end{tabular}

Values in Parentheses are annual averages.

cidents, we define three periods in this chapter slightly differently from in the previous chapter as Period I: 1974-1985, Period II: 1986-1996, and Period III: 1997-2007, respectively, because causes of accidents are under investigation from 2008.

\section{1) Causes of small airplane accidents}

Figure 6 shows the percentages of individual causes for small airplane accidents. Since one accident may occur as a result of a combination of multiple causes, the cumulative total number of causes may not equal the total number of accidents. As shown in Figure 6, 234 accidents (56.7\%) of all the 336 accidents are due to pilot error. In terms of other causes having a high percentage, equipment failure caused 64 accidents (15.5\%), adverse weather conditions accounted for 56 accidents (13.6\%), and improper maintenance resulted in 24 accidents (5.8\%). Thus, pilot error, equipment failure and weather factors account for more than $80 \%$ of all the causes. Especially, small airplanes are mostly controlled manually by the pilot during the entire flight including takeoff and landing rather than staying on autopilot, which resulted in the highest percentage of pilot error. Pilot error during takeoff and landing is classified into 4 major factors: operation, judgment, procedure and guidance. Operational errors include insufficient deceleration and premature veering. Judgment errors are typically a delay in making a decision to abort takeoff and a misreading of altitude. Procedural errors usually indicate mistakes in regular procedures such as failing to lower the landing gear. Misguidance occurs during training. The breakdown of the major error factors is as follows: 109 operational errors (46.6\%), 102 judgment errors $(43.6 \%), 45$ procedural errors (19.2\%) and 18 misguidance (7.7\%). The percentages provided for individual error factors represent their ratios to the total number of accidents. Since one accident may occur as a result of a combination of multiple errors, the total number does not amount to $100 \%$. Equipment failures consist of 42 engine failures (66.7\%), 14 malfunctions of the landing gear (22.2\%) and 7 defects in other parts of the aircraft $(11.1 \%)$. Accidents due to adverse weather conditions are mostly caused by clouds and fog, resulting in 27 accidents $(46.4 \%)$ and 5 accidents $(8.9 \%)$, respectively. These two factors alone account for more than half of the entire weather-triggered accidents. Most such accidents occur due to poor visibility. Other factors include wind and air turbulence, accounting for 13 accidents $(21.4 \%)$ and 9 accidents (16.1\%), respectively, from which we can see that aircraft are very susceptible to wind as they fly in the air.

In Figure 7, we show the causes of small airplane accidents based on classifying into two situations: during takeoff/landing and other situations(mostly during flight). From Figure 7, we can see the overall decrease in the frequency of major accident causes such as pilot error, bad weather, equipment failures and improper maintenance, in each period. The number of accidents due to pilot error factors during takeoff/landing dropped drastically from 77 in Period I to 38 in Period II.

Table 3 shows the changes in the number of small airplane accidents in the breakdown of pilot error factors foreach period. All types of errors remarkably decreasedin frequency from Period I to Period II. That is, there are various improvement efforts including enhanced operability, and new attempts at error proofing in order to avoid pilot error including judgment errors and procedural errors, such as warning tones and improved layout within the cockpit. Furthermore, the number of errors during training is also reduced, from which we can assume that there have also been some improvements in education. All of these contributed to the decrease in 


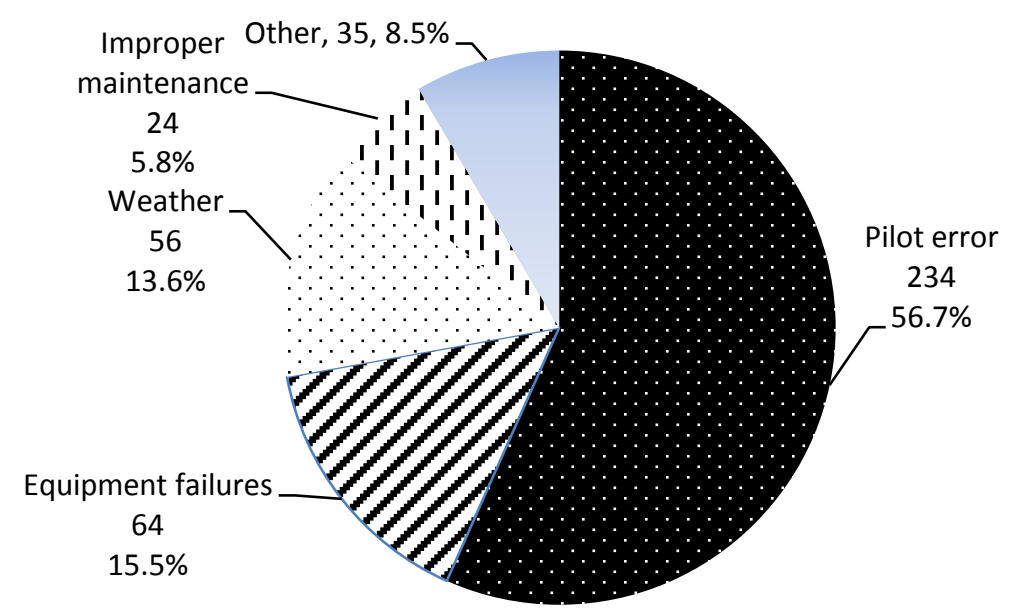

Figure 6. Accident causes for small airplanes (1974-2007).

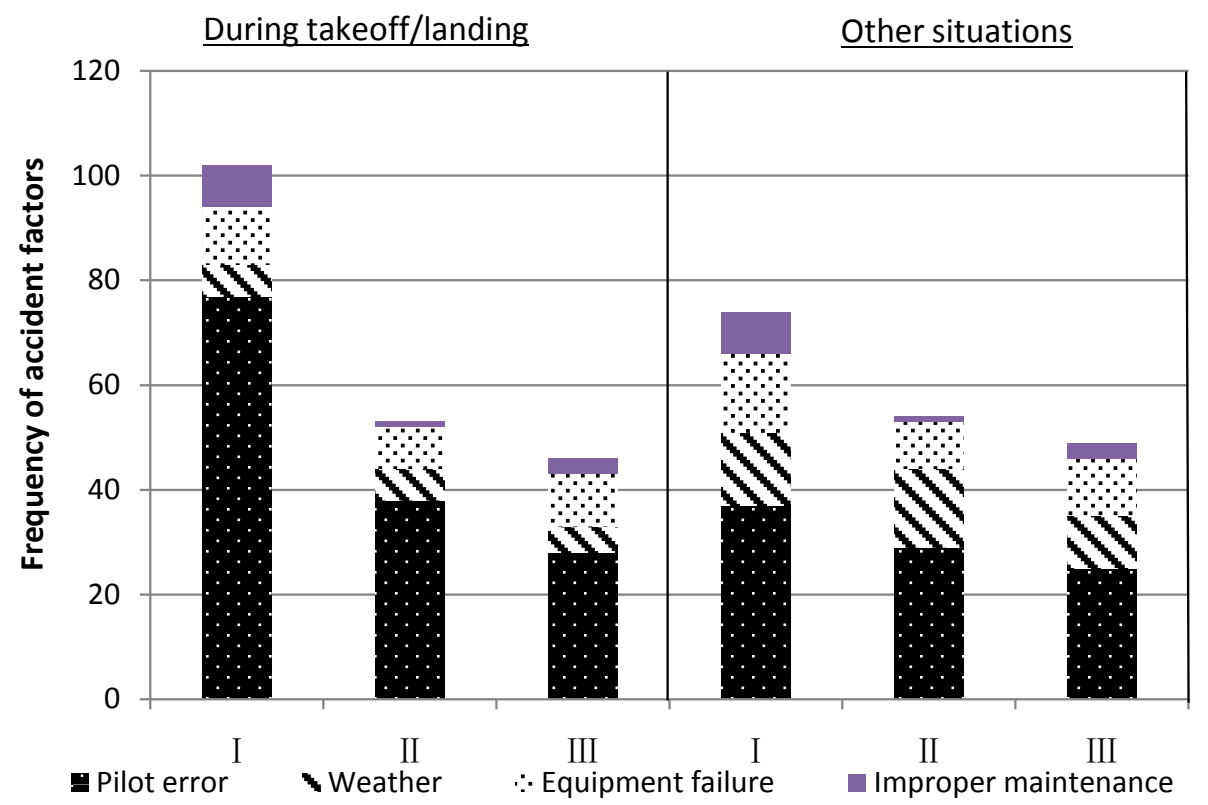

Figure 7. Accident factors for small airplanes (1974-2007).

Table 3. Types of pilot error for small airplanes accidents.

\begin{tabular}{cccccccccccc}
\hline Period & During TL & \multicolumn{10}{c}{ During FL } \\
\hline & OE & JE & PE & MG & Total & OE & JE & PE & MG & Total \\
\hline I & 40 & 19 & 20 & 10 & 89 & 18 & 23 & 3 & 1 & 45 \\
II & 23 & 10 & 8 & 3 & 44 & 11 & 25 & 0 & 0 & 36 \\
III & 12 & 6 & 11 & 2 & 31 & 5 & 19 & 3 & 2 & 29 \\
Total (\%) & $75(45.7)$ & $35(21.3)$ & $39(23.8)$ & $15(9.1)$ & $164(100.0)$ & $34(30.9)$ & $67(60.9)$ & $6(5.5)$ & $3(2.7)$ & $110(100.0)$ \\
\hline
\end{tabular}

TL: Take Off and Landing; FL: Flight; OE: Operational Errors; JE: Judgment Errors; PE: Procedural Errors; MG: Misguidance.

the number of small airplane accidents. There are still old models of aircrafts in service. As they are replaced by new models, we expect that the number of accidents due to pilot error will further decrease.Accidents during flight are mostly due to judgment errors in pilot errors, the number of which is 23, 25 and 19 in Periods I, II and 
III, respectively. Though judgement errors during flight are very likely to result in fatalities, we can see that technical improvements are far from enough to help reduce such errors. A solution to this issue is expected to contribute greatly to a reduced number of accidents and fatalities.

\section{2) Causes of large airplane accidents}

There were 109 large airplane accidents in total during the period from 1974 to 2007. Accident causes consist of weather, pilot error, equipment failure and improper maintenance, which account for 38 accidents (32.2\%), 37 (31.4\%), $12(10.2 \%)$ and 4 (3.4\%), respectively, as shown in Figure 8. The other 27 accidents are due to birds, collisions with obstacle at the airport, deaths by disease, and some other unknown reasons. While pilot error is less than that of small airplanes in terms of the percentage, they still account for a major part of the causes of large airplane accidents. As shown in Figure 9, about $90 \%$ of accidents are due to air turbulence and wind, from which we can see that large airplanes are very susceptible to strong wind. Comparing accident factors during takeoff and landing with those that occurred in other situations, the biggest factor is pilot error, which accounts for 28 accidents (51.9\%) that occurred during takeoff and landing. On the other hand, accidents that happened in other situations, in other words, those that happened mainly during flight, are mostly due to weather factors, accounting for 26 accidents $(40.6 \%)$. In Figure 10, the period is divided into three periods I, II, and III. Further, large airplane accidents are classified into two situations: during takeoff and landing and other

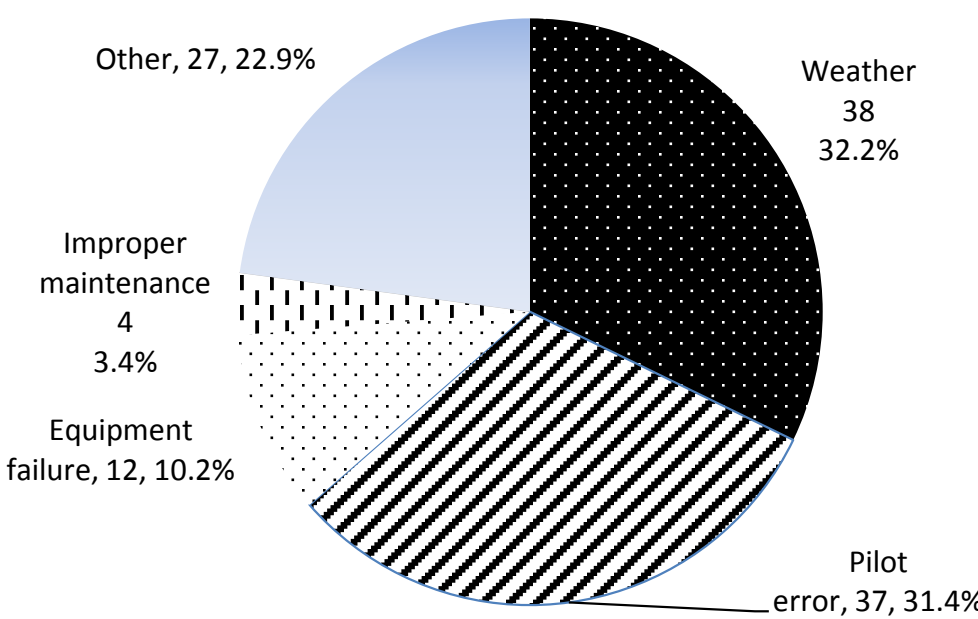

Figure 8. Accident factors for large airplanes (1974-2007).

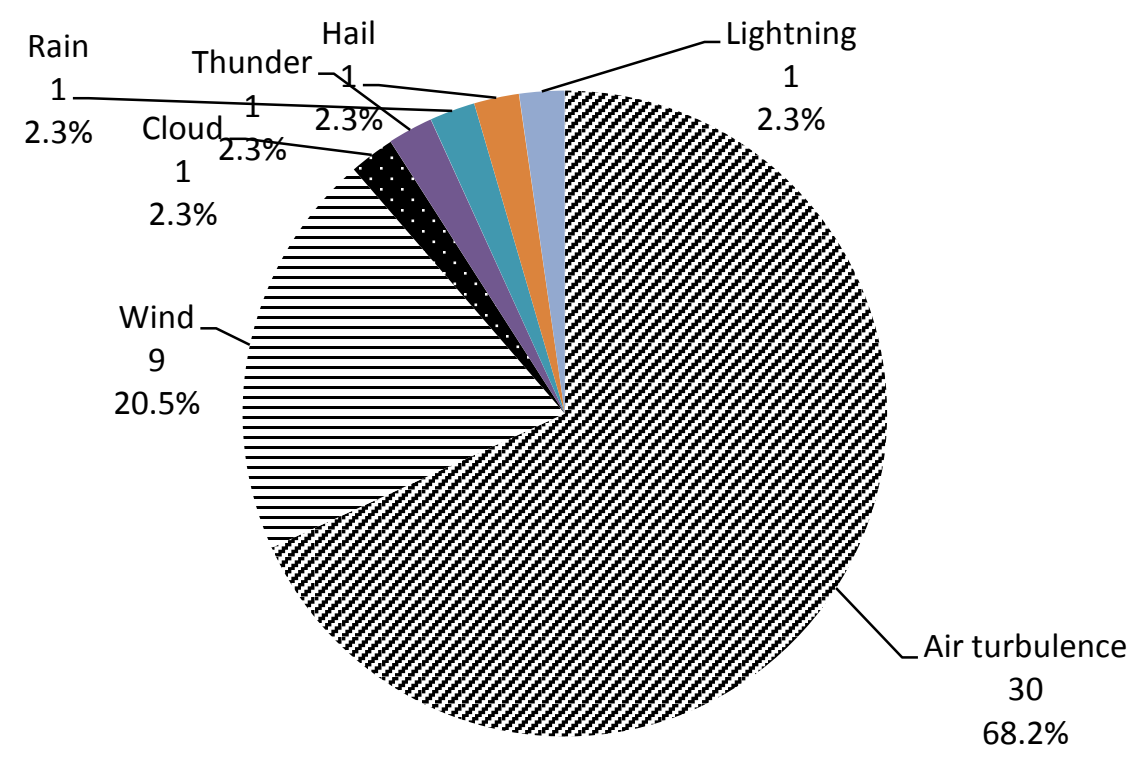

Figure 9. Weather factors for large airplane accidents (1974-2007). 


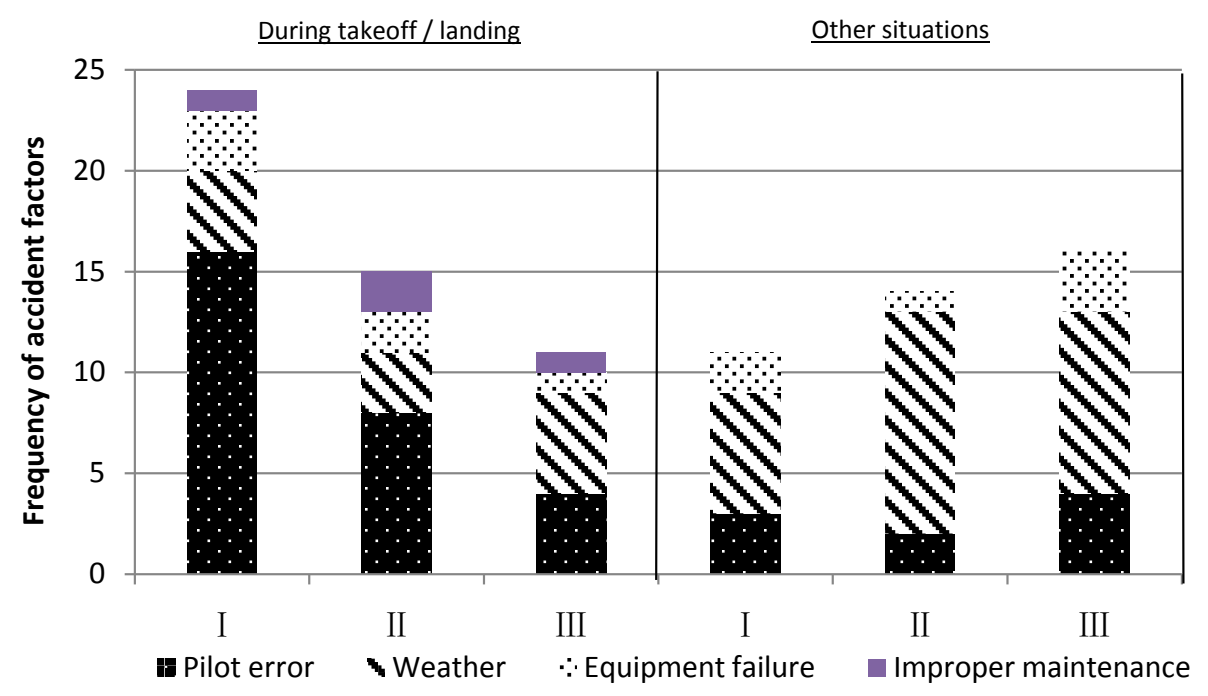

Figure 10. Accident factors for large airplanes (1974-2007).

Situations (mostly during flight). We can see that the number of accidents decreases substantially from Period I to Period II. This is mostly due to technological developments in aviation policy concerning air traffic services, aircraft and airport control, all of which were rapidly upgraded after two big accidents in 1971 before Period I. Such developments are likely to be the result of the implementation of various measures, including a ban on flying in clouds, upgrading of traffic lanes for private airlines and the Self Defense Forces, installation of radars, and securing a sufficient number of air traffic controllers. The number of accidents due to weather in Period I, II and III are 10, 14 and 14, respectively. This implies that reducing aircraft accidents due to weather is not so easy.

Most accident causes during takeoff and landing are due to pilot error, whereas those in other situations are attributed to weather conditions. Table 4 shows the changes in frequency for each type of pilot error during takeoff and landing, and flight for each period from 1974 to 2007.Pilot errors due to operational errors and judgment errors are on a decreasing trend. This is presumably attributed to the improvement in aircraft performance and efforts associated with Crew Resource Management (CRM). The increased number of operational errors during flight in Period III is due to excess maneuvering by the pilot. The number of accidents due to adverse weather conditions was $6(54.5 \%)$ in Period I, which increased to 11 (78.6\%) in Period II. This is possibly because of the recent shifting weather patterns as a result of global warming. However, it decreased to $9(56.3 \%)$ in Period III, 2 accidents less than in Period II. This decrease is probably due to an increase in pilots' knowledge and technological development. In 1982, Delta Air Lines Flight 191 was hit by air turbulence and crashed during final landing in the United States, killing 135 people. After this accident, the U.S. Federal Aviation Administration (FAA) encouraged improvements in weather radar technology and revisions in technical training (see Rodriguesand Cusick [9]).

The number of pilot errors in other situations was $2(14.3 \%)$ in Period II and $4(25.0 \%)$ in Period III. The frequency of equipment failures also increased slightly from 1 (7.1\%) in Period II to 3 (18.8\%) in Period III. We assume that this is due to the drastic increase in aviation demand. However, the increase in the number of pilot errors is presumably due to the following factors. In Period I, the factors include mere operational errors by the pilot, insufficient communication with the air traffic controller and incorrect assumptions. None of them are external factors such as natural phenomena, which implies there is still room for improvement. On the other hand, a large number of accidents in Periods II and III are due to natural phenomena and incorrect responses thereto. Accidents due to the factors in Period I are likely to be reduced relatively easily by technological developments, intensive training and improved communication methods. On the contrary, factors associated with natural phenomena have not yet been eliminated, as air turbulence occurs quite frequently and appropriate responses thereto are quite problematic.

\section{3) Causes of helicopter accidents}

Figure 11 shows the causes of helicopter accidents. Through the entire period, there were 396 helicopter accidents, the causes of which are mainly pilot error, accounting for 276 accidents, nearly $70 \%$ of all accidents. 


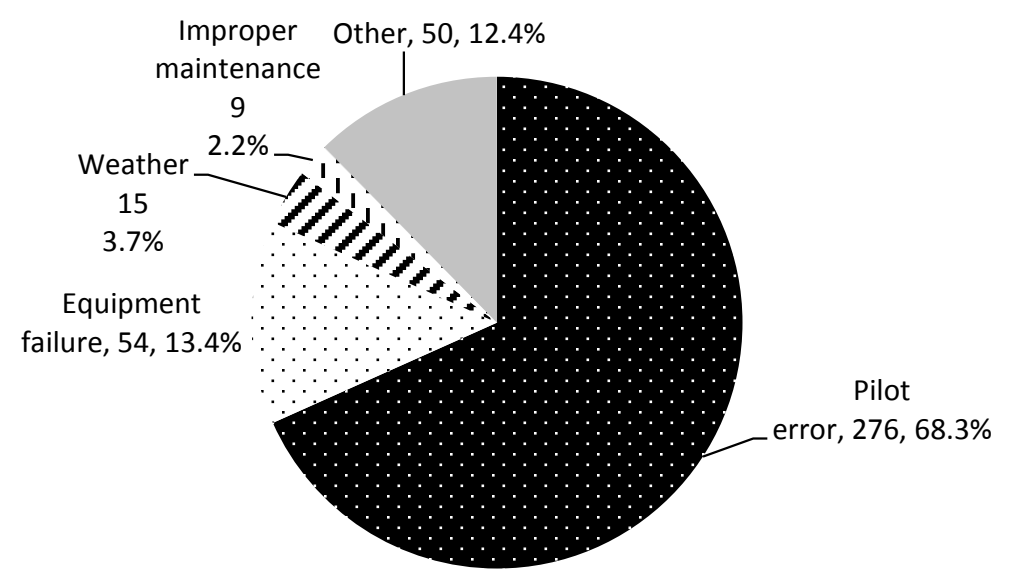

Figure 11. Accident causes for helicopters (1974-2007).

Table 4. Types of pilot error for large airplanes accidents.

\begin{tabular}{cccccccccccc}
\hline \multirow{2}{*}{ Period } & \multicolumn{9}{c}{ During TL } & \multicolumn{3}{c}{ During FL } \\
\cline { 2 - 11 }$y$ & OE & JE & PE & MG & Total & OE & JE & PE & MG & Total \\
\hline I & 11 & 4 & 2 & 0 & 17 & 1 & 2 & 1 & 0 & 4 \\
II & 6 & 4 & 2 & 0 & 12 & 1 & 1 & 0 & 1 & 3 \\
III & 4 & 1 & 0 & 1 & 6 & 3 & 1 & 0 & 1 & 5 \\
Total (\%) & $21(60.0)$ & $9(25.7)$ & $4(11.4)$ & $1(2.9)$ & $35(100.0)$ & $5(14.3)$ & $4(11.4)$ & $1(2.9)$ & $2(5.7)$ & $12(100.0)$ \\
\hline
\end{tabular}

TL: Take Off and Landing; FL: Flight; OE: Operational Errors; JE:Judgment Errors; PE: Procedural Errors; MG: Misguidance.

The number of major accident factors including pilot error (276 accidents, $68.3 \%$ ), equipment failure (54 accidents, $13.4 \%)$, weather $(15,3.7 \%)$, and improper maintenance $(9,2.2 \%)$ accounts for almost $90 \%$ of all accidents. Thus, we know that almost $70 \%$ of helicopter accidents are due to various types of pilot error. Weather factors consist of fog accounting for 5 accidents, clouds and air turbulence, each of which accounts for 3 accidents, and wind and snow, each of which accounts for 2 accidents. Here, we can see that low visibility due to fog and clouds, air turbulence and wind are all closely related to the adverse impact on the operation of aircraft.

Figure 12 shows the changes in the frequencies of major helicopter accident factors in individual periods from Period I to Period III. The major accident factors are pilot error, weather, equipment failure and improper maintenance. From Figure 12, we find that helicopter accidents occur more often during flight than during takeoff and landing. This is in contrast with small and large airplanes, which have more accidents during takeoff and landing than during flight. There is an increase in the percentage of accidents due to pilot error that occurred mainly during flight, rather than during takeoff and landing, whereas those due to other factors decreased.This indicates that it is possibly more difficult to prevent pilot error during flight than to reduce other accident factors.

The most common use for helicopters at the time of an accident is crop-dusting or other similar operations which accounted for 145 accidents (36.6\%) followed by the transfer of personnel which accounted for 113 accidents (28.5\%), load carrying which accounted for 63 accidents (15.9\%), 37 accidents $(9.3 \%)$ during training, transporting the body of a helicopter which accounted for 20 accidents (5.1\%), and 18 accidents during maintenance flights (4.5\%). As agricultural chemicals for rice are intensively applied from June to August, we can see the seasonal feature that many helicopter accidents occur in summer. As we the investigate purposes of the use of helicopters involved in accidents for each period, we note that the frequency of crop-dusting purposes has decreased. One of the factors for such a change is possibly that crop-dusting is no longer performed by manned helicopters, which have been replaced by unmanned helicopters.

The number of accidents decreased from 192 in Period I to 129 in Period II, dropping by about 30\%, which further decreased by $40 \%$ to 75 in Period III.The number of accidents due to judgment errors in pilot error is 150 , accounting for more than $70 \%$. Table 5 shows the breakdown of pilot error for helicopter accidents. Accidents 


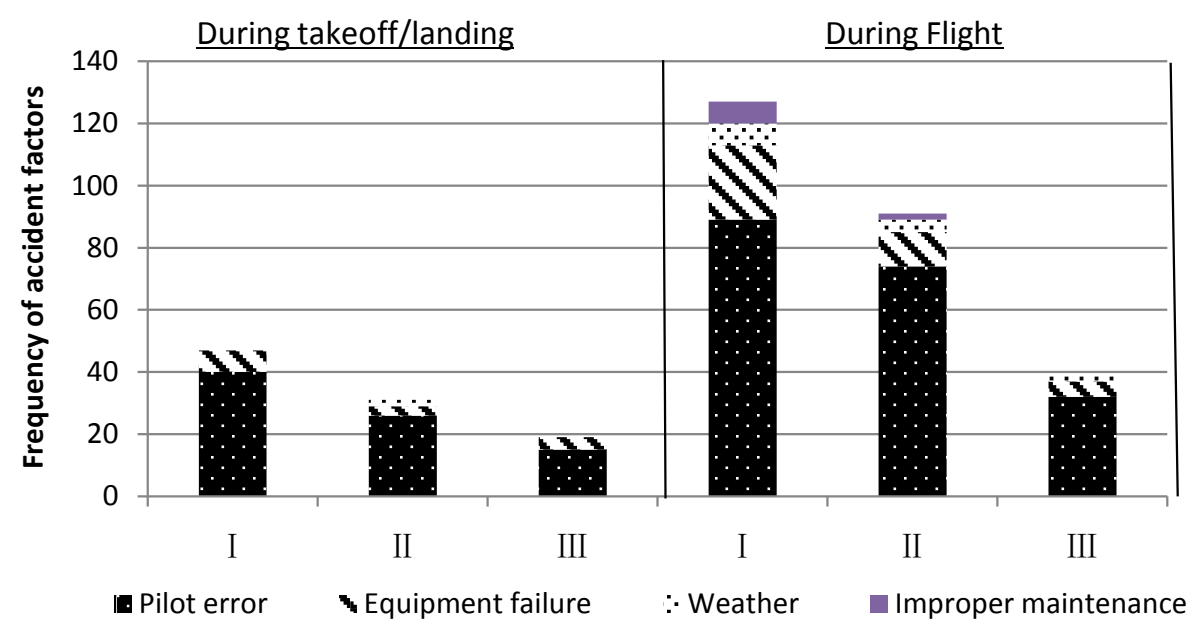

Figure 12. Frequency of accident factors for helicopters (1974-2007).

Table 5. Types of pilot error for helicopters accidents.

\begin{tabular}{|c|c|c|c|c|c|c|c|c|c|c|}
\hline \multirow{2}{*}{ Period } & \multicolumn{5}{|c|}{ During TL } & \multicolumn{5}{|c|}{ During FL } \\
\hline & $\mathrm{OE}$ & $\mathrm{JE}$ & PE & MG & Total & OE & $\mathrm{JE}$ & $\mathrm{PE}$ & MG & Total \\
\hline I & 28 & 14 & 0 & 7 & 49 & 20 & 73 & 0 & 0 & 93 \\
\hline II & 21 & 7 & 0 & 2 & 30 & 21 & 55 & 1 & 1 & 78 \\
\hline III & 14 & 4 & 2 & 2 & 22 & 6 & 22 & 0 & 0 & 28 \\
\hline Total (\%) & $63(62.4)$ & $25(24.8)$ & $2(2.0)$ & $11(10.9)$ & $101(100.0)$ & 47 (23.6) & $150(75.4)$ & $\begin{array}{c}1 \\
(0.5)\end{array}$ & $1(0.5)$ & $199(100.0)$ \\
\hline
\end{tabular}

TL: Take Off and Landing; FL: Flight; OE: Operational Errors; JE: Judgment Errors; PE: Procedural Errors; MG: Misguidance.

due to judgment errors by the pilot, collisions in particular, seem to be very difficult to eliminate, even if helicopter technologies are mechanically and electronically improved. These days, however, various new systems have been established, such as one that produces a warning tone or activates an automatic braking function when recognizing an obstacle, which has already been utilized in cars. When they are further upgraded and linked to GPS so that they can be applied to helicopters, the number of accidents due to collisions may possibly decrease.

\subsection{Accident Prevention Measures and Their Effects}

In order to prevent aircraft accidents, we consider the following three elements to be important: i) technology innovation for accident prevention and aircraft design; ii) training of cabin attendants, airport traffic controllers and mechanics; iii) air traffic public administration and policy making.

Regarding technology innovation for accident prevention and aircraft design, prevention systems for collision with mutual aircraft or with the ground, avoidance of human error by introducing autopilot systems, safety designs preventing fatal break down in case of some functional defects and inspection methods for old aircraft can possibly prevent aircraft accidents. Additionally, designs for considering survival factors are also important in order to increase the survival rate in case of accidents. In the past, the Minimum Safe Altitude Warning (MSAW) was developed and introduced in ground control in 1975, the Ground Proximity Warning System (GPWS) was required in commercial aircraft in 1977. In the same year, the Radar Data Processing system (RDP) and the Automated Radar Terminal System (ARTS) were installed and a radar network system covering all the airspace of Japan was completed, resulting in the enhancement of the safety of flight and the efficiency of air traffic control as described by Sugie [10], Yanagida [11] and Tsumajika [12]. Shimada [13] mentioned that a glass cockpit effectively preventing pilot error was installed in 1981. In 1978, the adoption of a new design principle called "Damage Tolerance Design" was announced in Japan. Damage tolerance design includes a structure that prevents a fatal breakdown even if there is a minor scratch less than a few millimeters in size that may not be de- 
tected during a regular checkup.

The second important element for preventing accidents is training of all concerned personnel. Nakasuga [5] suggested the necessity of psychological training for pilots especially in case of "panic". Also we believe that improving communication with other aircrafts as well as with controllers, the copilot and cabin attendants in an aircraft, improving inspectors' skill and enhancing general health management are very important for reducing aircraft accidents. After the accidents in the 1970s, Japan Airlines (JAL) tightened its standards for the employment examination for pilots and the promotional examination for captains, and established the Special Committee on Safety Measures, in which an intensive reanalysis of past accidents was conducted in order to take preventive measures against common pilot errors (see Yanagida [11]). In the 1980s, JAL was the first to adopt cockpit resource management, which was created from the viewpoint of human behavior, focusing on how to further enhance performance as a team and to create a related training method in order to eliminate human error. Sincethen, Crew Resource Management (CRM) for all crew in aircraft has been adopted in each airline (Sugie [10], Yanagida [11]). In response to an accident due to mental illness in 1982, the Council for Civil Aviation conducted deliberations where measures were undertaken to improve the health management of and operational control for pilots. The establishment of the Japan Aeromedical Research Center was part of such measures (see Yamamoto [14]).

Finally, we emphasize the importance of air traffic public administration and policy making. According to Masui and Takahashi [15] and Tazaki [16], on July 3, 1971, Toa Domestic Airlines Flight 533, a YS-11 called "Bandai" en route from Sapporo to Hakodate Airport crashed into the mountainside of Yokotsudake due to inclement weather, killing all 68 people on board. After the Bandai accident, while the Transport Ministry was still reviewing the enhanced aviation security measures for aviation administrative agencies on July 30, 1971, All Nippon Airways Flight 58, a Boeing 727 airliner, collided with a Japan Air Self-Defense Force F-86F fighter jet over Shizukuishi, Iwate Prefecture, killing all 162 people on board. In response to these two accidents, the government drew up the Outline of Aviation Security Measures, which included accelerated improvements in aviation security facilities such as the Instrument Landing System (ILS), the VHP Omni directional Range(VOR) and the Distance Measuring Equipment (DME), the prompt introduction of a long-range radar surveillance network covering all parts of Japan, other safety measures such as securing sufficient numbers of aviation security personnel, including air traffic controllers, as well as reviewing the establishment of related administrative agencies in order to improve the current aviation security framework. Additionally, they established "the outline of air traffic safety emergency measure". Thus, the government decided to separate training and testing areas for military and civilian use. Further, as recommended by the ICAO, flights in Visual Meteorological Condition (VMC) were prohibited, eliminating rules that allowed flights at varying altitudes. "The memorandum regarding adjustments between the aviation administration by the transport ministry and operations of the self-defense forces" was revised and incorporated to serve as a report focusing on air traffic safety, rather than for the old operational coordination purposes. Accelerated modernization of the air traffic control system was strongly agreed upon within the Japan Civil Aviation Bureau (JCAB). The JCAB established the flight control investigation headquarters, in which emergency security measures were formulated and the air control system was reviewed.

We can say that pilot, aircraft, airports, cabin attendants, airport traffic controllers as well as technology and techniques comprise construct ageneral technical system. Therefore, comprehensive policy making and enforcement from the safety perspective of the technical system are important, and subsequently, we can reduce the number of accidents and mitigate the damage. In addition, Shiroyama et al. [4] emphasized that surveying system and approach to the bereaved are also important.

In order to reduce the number of accidents, we consider that measures against adverse weather conditions for large airplanes are effective, whereas those against pilot error are necessary for small airplanes and helicopters. As for large airplanes, measures against air turbulence are essential. Regarding small airplanes, as described in Chapter 3.1, the number of judgment errors during flight has hardly decreased. Therefore, technological innovations and improved education that could help reduce judgment errors would be effective. It would also be necessary to adopt error proofing that prevents procedural errors during takeoff and landing and to enhance training in order to avoid operational errors. Although error proofing has already been adopted in the latest model of small airplanes, airplanes manufactured 30 years ago may be involved in accidents today. Accordingly, it would probably be a good idea to develop a device for error proofing that can also be installed in older aircraft, and to create regulations that require a mandatory application of such a device. As for helicopters, there are a large 
number of collisions with obstacles during flight. Therefore, it would be helpful to have a system in which enhanced preliminary observation is required. Also the authorities can provide advance warning of the danger of obstacles upon receipt of flight notification.

Other systems have also been developed such that warning tones are emitted or a control function such as automatic braking is activated when obstacles are detected like the ones utilized in cars. They may possibly be upgraded so they are connected with the GPS and are thus able to issue a warning based on the collision prediction. Their utilization in small airplanes and helicopters may possibly contribute to the further decrease in the number of collision accidents.

\section{Mathematical Model Analyses on Airplane/Helicopter Accidents}

\subsection{Aviation Demand and Airplane/Helicopter Accidents}

Figure 13 shows the changes in the number of landings and the value of GDP (Gross Domestic Product). Up to the year 1991, aviation demand increased as the GDP grew. From 1992 to 1998, the aviation demand stayed on an upward trend despite the downturn growth in the GDP. After 1998, the aviation demand slowed as well, taking a downward turn in 2007. In the future, we expect the possibility of high growth in aviation demand due to a possible increase in the GDP and upgrading of airports, among other factors.

When we plot the number of aircraft landings on the horizontal axis, and the number of accidents on the vertical axis using the data from 1974 to 2010, we obtain the graph as shown in Figure 14. If we define Japan's economic growth as the explanatory variable $(x)$ and the number of aircraft landings as the dependent variable $(y)^{1}$, the parameter estimate for the simple regression model using the data between 1974 and 1991 is givenas follows:

$$
y=0.772 x+4.13
$$

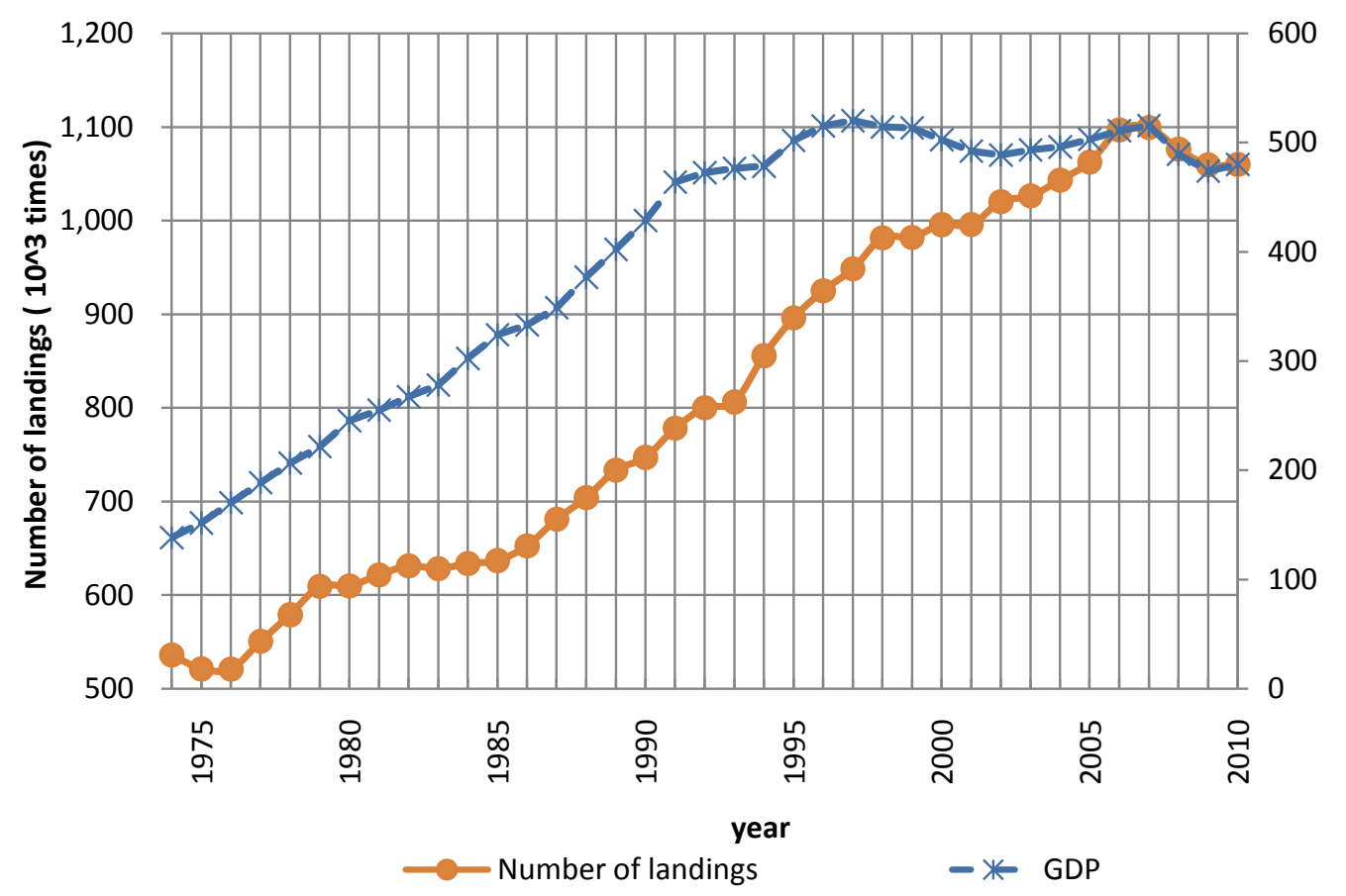

Figure 13. Aircraft landings and GDP (1974-2010). Source: Ministry of Internal Affairs and Communications Statistics Bureau, Japan Statistical Yearbook, 1981, 1985, 1989, 1993/94, 1997, 2002, 2007, 2010, 2014, Japan Statistical Association [17].

${ }^{1}$ Source: Ministry of Internal Affairs and Communications Statistics Bureau, Japan. Statistical Yearbook, 1981, 1985, 1989, 1993/94, 1997, 2002, 2007, 2010, 2014, Japan. Statistical Association [17]. 


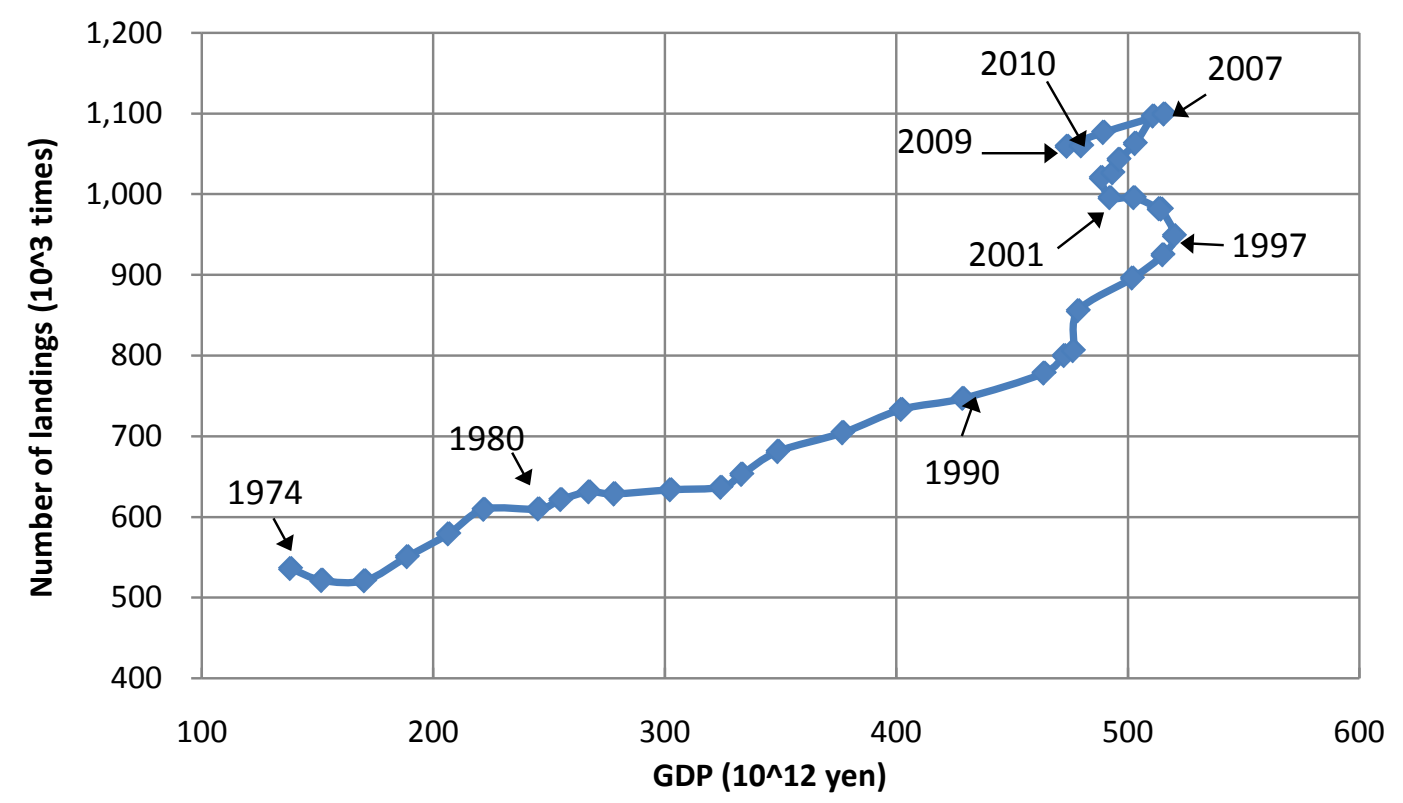

Figure 14. Changes in GDP and the number of aircraft landings (1974-2010).

Goodness of fit of the above model (1) is $R^{2}=0.976$, and the values in parentheses ( ) are $t$-values. From the above result we find that the number of aircraft landings grows around 772 corresponding to the unit increase ( $10^{12}$ yen) of GDP during the period from 1974 to 1991 . The economy slowed down after 1991 and the GDP stayed aound 400 trillion yen, whereas the number of landings increased by approximately 20 thousand per year until 2005.

From the regression result in (1), we can see that aviation demand increases along with economic growth. Before 1991, GDP growth of 100 trillion yen corresponded to an increase in the number of landings by 77 thousand times.

We selectrailway transportation demand and automobile registration demand as the factors influencing aviation demand. Then we carry out a multiple linear regression analysis based on the data during the period from 1974 to 2004. If we define railway passengers' traveling distance demand $\left(10^{8}\right.$ passenger-kilometer $)\left(x_{1}\right)^{2}$, and the number of registered cars (100 units) $\left(x_{2}\right)^{3}$, as the explanatory variables and the number of aircraft landings $(y)$ as the dependent variable, the parameter estimates of a multiple linear regression model areobtained as follows:

$$
y=0.194 x_{1}+1.32 x_{2}+240724.4
$$

The goodness of fit of the above model (2) is $R^{2}=0.998$, and the values in parentheses ( ) are $t$-values. We know that the Japanese railway transportation demand has been increasing up to around 1990, then has been stagnant until 2004. On the other hand the automobile registration demand has been almost constantly increasing similar to the aviation demand which has been increasing throughout almost the whole period. Thus, we find that the automobile registration demand has been contributing more effectively to the increase of the aviation demand expressed by the number of aircraft landings.

When we plot the number of flights on the horizontal axis, and the number of accidents on the vertical axis from 1974 to 2010, we obtain the graph as shown in Figure 15. Now, in order to identify the relation between aviation demand and the number of aircraft accidents we define a quadratic function model between two variables: the number of aircraft landings (100 thousand times) $(x)$ as the explanatory variable and the aircraft accident figure $(y)$ as the dependent variable. The parameter estimates of a multiple linear model based on the data between 1974 and 1998 are given as follows:

\footnotetext{
${ }^{2}$ Source: Statistical Bureau, Ministry of Internal Affairs and Communication.

${ }^{3}$ Source: Automobile Inspection and Registration Information Association.
} 


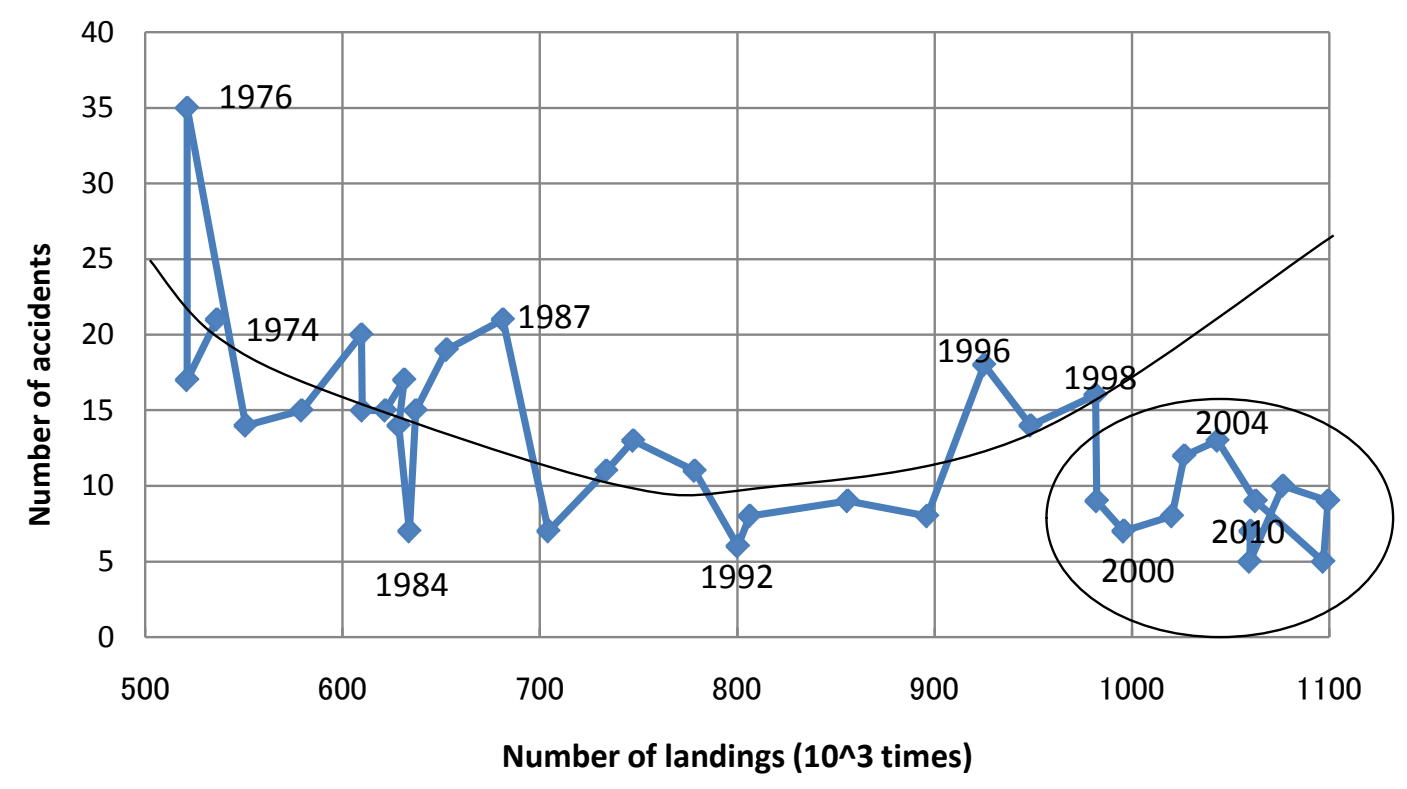

Figure 15. Aircraft landings and accidents (1974-2010).

$$
y=1.77 x^{2}-28.2 x+122.3
$$

The goodness of fit of estimate Equation (3) is $R^{2}=0.443$, and the values in parentheses ( ) are $t$-values. The minimum of $y$ in the above quadratic function (3) is obtained at around $x=7.97$. This implies that accidents decrease as the number of landings increases and when the number of landings is around 800 thousand, the number of accidents is at a minimum. In other words, the minimum value is obtained between 1992 when there were about 800,000 landings and 1995 when there were about 900,000 landings. According to the actual data, there were 6 accidents in 1992, 8 in 1993, 9 in 1994, and 8 in 1995, which is consistent with the period when the least number of accidents should occur in theory. Up to 1991, this is attributed to the progress in accident preventive measures, which was greater than the increase in the aviation demand. Specifically, as described below, while the air traffic services developed, the related technologies including aircraft and the air traffic control also advanced. There were also apparent effects of human resource development through education and training until 1991. However, after 1991, we note that accidents that are very hard to deal with cannot be prevented completely as old and decrepit airplanes are still in service, and it is very difficult to supervise privately owned airplanes. In the future, aviation demand and the number of accidents may increase slightly due to the improvement of airports and an increased number of LCCs (Low Cost Carriers). There is also a fear that unexpected airplane accidents may occur as new technologies are introduced and the wave of computerization prevails. However, we expect no major variations in the number of accidents.

\subsection{Mathematical Model for Intervals of Accident Occurrence}

Figure 16 and Figure 17 show the distribution data of the number of days in the interval of accident occurrence in descending order in terms of airplanes (small and large) and helicopters, respectively. We divided our entire study period from 1974 to 2010 into three parts: Periods I, II and III. Then, we examined the goodness of fit of individual distribution data in terms of the exponential distribution, lognormal distribution, beta distribution and gamma distribution, utilizing "Statistically Fit Software version 2" provided by Green Mountain Software. The results of the goodness of fit of these distributions are indicated in Table 6 and the estimated values of the parameters are shown in Table 7. The values in Table 6 are the results of a chi-squared test. Those with an underline are not rejected in individual tests, and highlighted data shows the most fit data among all statistical models. Regarding the exponential distribution, 13 probability distributions of occurrence intervals out of 16 probability distributions of the number of occurrence days were not rejected in a chi-squared test. Regarding the airplanes 
Mean value:29.0

Standard deviation:32.8

$n=466$

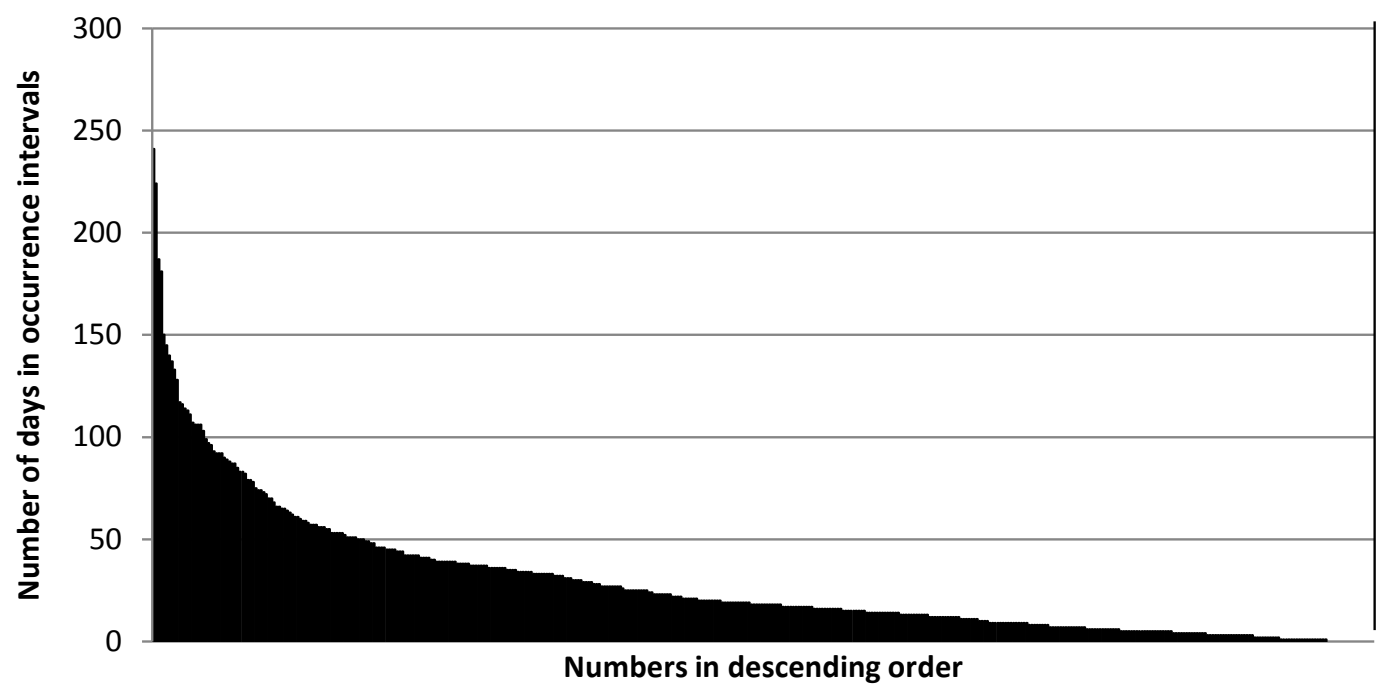

Figure 16. Number of days in occurrence intervals for airplane accidents (1974-2010).

Table 6. Results of the goodness of fit tests (1974-2010).

\begin{tabular}{|c|c|c|c|c|c|}
\hline \multirow{2}{*}{ Type of aircraft } & \multirow{2}{*}{ Period } & \multicolumn{4}{|c|}{ Probability distribution } \\
\hline & & Exponential & Lognormal & Beta & Gamma \\
\hline \multirow{4}{*}{ Airplane (large/small) } & Entire period & 29.90 & 34.50 & 40.80 & 33.80 \\
\hline & I & 8.59 & 40.70 & 13.10 & 18.50 \\
\hline & II & 10.30 & 10.60 & 8.21 & 8.43 \\
\hline & III & 3.43 & 3.77 & 6.85 & 5.48 \\
\hline \multirow{4}{*}{ Small airplane } & Entire period & 18.10 & 38.10 & 28.10 & 29.60 \\
\hline & I & 6.80 & 12.80 & 21.20 & 15.80 \\
\hline & II & 11.90 & 10.70 & 17.00 & 20.70 \\
\hline & III & 6.76 & 5.26 & 11.50 & 9.40 \\
\hline \multirow{4}{*}{ Large airplane } & Entire period & 5.83 & 13.70 & 2.66 & 10.60 \\
\hline & I & 4.22 & 3.35 & 2.91 & 4.22 \\
\hline & II & 0.97 & 1.78 & 3.14 & 1.51 \\
\hline & III & 1.75 & 2.75 & 0.25 & 1.25 \\
\hline \multirow{5}{*}{ Helicopter } & Entire period & 39.30 & 35.10 & 60.70 & 39.60 \\
\hline & I & 14.40 & 8.74 & 21.20 & 11.60 \\
\hline & & & & & \\
\hline & II & 19.40 & 15.70 & 15.20 & 17.80 \\
\hline & III & 12.70 & 5.37 & 16.20 & 16.70 \\
\hline
\end{tabular}

Shaded values in the table indicate the highest goodness of fit. Those with an underline were not rejected in individual tests. 
Mean value: 32.5

Standard deviation:45.7

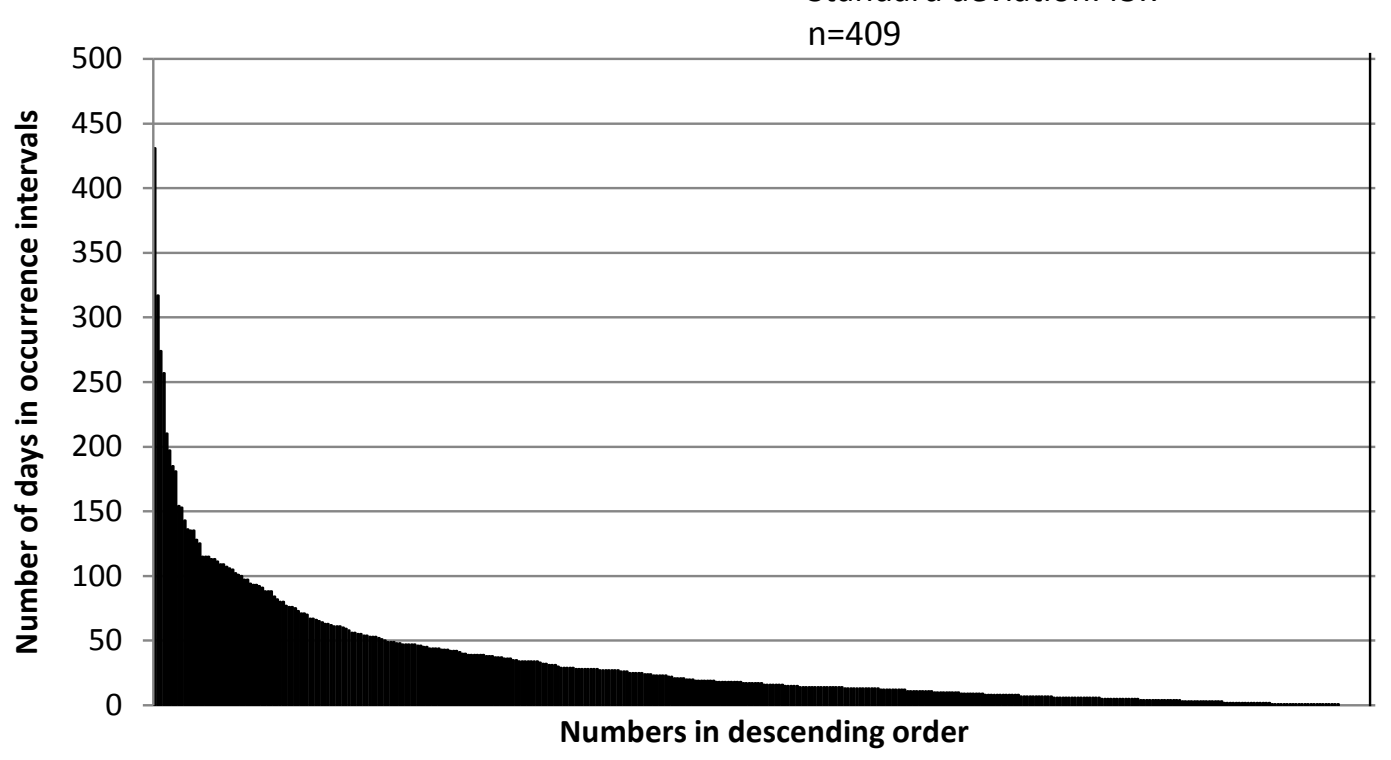

Figure 17. Number of days in occurrence intervals for helicopter accidents (1974-2010).

Table 7. Estimated parameters in individual distributions (1974-2010).

\begin{tabular}{|c|c|c|c|c|c|c|c|c|c|}
\hline \multirow{3}{*}{$\begin{array}{l}\text { Types of } \\
\text { aircraft }\end{array}$} & \multirow{3}{*}{ Period } & \multicolumn{8}{|c|}{ Probability distribution } \\
\hline & & \multirow{2}{*}{$\begin{array}{c}\text { Mean value } \\
\text { (Actual measurement) }\end{array}$} & \multirow{2}{*}{$\begin{array}{c}\text { Exponential } \\
\text { Beta }(1 / \lambda)\end{array}$} & \multicolumn{2}{|c|}{ Lognormal } & \multicolumn{2}{|c|}{ Beta } & \multicolumn{2}{|c|}{ Gamma } \\
\hline & & & & $\mathrm{Mu}(\mu)$ & $\operatorname{Sigma}(\sigma)$ & $p$ & $q$ & Alpha & Beta \\
\hline \multirow{4}{*}{$\begin{array}{c}\text { Airplane } \\
\text { (large/small) }\end{array}$} & Entire period & 29.0 & 29.0 & 2.8 & 1.2 & 0.8 & 27.6 & 1.1 & 26.4 \\
\hline & I & 21.4 & 21.4 & 2.6 & 1.1 & 1.0 & 7.6 & 1.3 & 17.1 \\
\hline & II & 30.2 & 30.2 & 2.9 & 1.2 & 0.8 & 3.9 & 1.1 & 27.5 \\
\hline & III & 40.6 & 40.6 & 3.2 & 1.2 & 1.0 & 9.3 & 1.1 & 37.2 \\
\hline \multirow{4}{*}{ Small airplane } & Entire period & 38.6 & 38.6 & 3.1 & 1.2 & 0.9 & 10.7 & 1.0 & 36.8 \\
\hline & I & 27.8 & 27.8 & 2.9 & 1.1 & 1.1 & 9.0 & 1.2 & 23.2 \\
\hline & II & 40.6 & 40.6 & 3.2 & 1.2 & 0.9 & 10.7 & 1.1 & 37.2 \\
\hline & III & 55.9 & 55.9 & 3.5 & 1.2 & 0.8 & 3.6 & 1.0 & 53.8 \\
\hline \multirow{4}{*}{ Large airplane } & Entire period & 113.0 & 113.0 & 4.2 & 1.2 & 0.8 & 2.3 & 1.1 & 100.8 \\
\hline & I & 91.2 & 91.2 & 4.1 & 1.2 & 0.8 & 1.4 & 1.2 & 72.9 \\
\hline & II & 118.1 & 117.1 & 4.3 & 1.1 & 0.8 & 1.7 & 1.2 & 98.2 \\
\hline & III & 138.6 & 134.6 & 4.5 & 1.2 & 0.8 & 1.3 & 1.3 & 104.1 \\
\hline \multirow{4}{*}{ Helicopter } & Entire period & 32.5 & 32.5 & 2.8 & 1.3 & 0.8 & 8.9 & 0.8 & 38.7 \\
\hline & I & 22.8 & 22.8 & 2.5 & 1.2 & 0.8 & 4.6 & 1.0 & 23.4 \\
\hline & II & 32.2 & 32.2 & 2.8 & 1.3 & 0.8 & 17.5 & 0.9 & 37.0 \\
\hline & III & 55.4 & 55.4 & 3.3 & 1.3 & 0.8 & 10.2 & 0.8 & 65.8 \\
\hline
\end{tabular}


(small and large), 6 out of 12 distributions indicated the highest degree of goodness of fit. If those falling into the second highest are included, 10 distributions have a high degree of goodness of fit with the exponential distribution. As the mean value and the standard deviation are close, which is one of the properties of the exponential distribution, we can say that the probability of accident occurrence has the property of the exponential distribution. Accordingly, we herein define a formula by the exponential distribution. The probability density function of the exponential distribution is provided as follows:

$$
f(t)=\lambda e^{-\lambda t}
$$

When using the parameter estimate $\hat{\lambda}$, the expected value of the occurrence interval $(1 / \hat{\lambda})$ in terms of airplanes (small and large) is 33 days during the entire period, while it is 23, 31 and 44 days in Period I, II and III, respectively. In the same manner, regarding small airplanes, it is 39 days (entire period), 28 (Period I), 41 (Period II), and 56 days (Period III). Regarding large airplanes, it is 113 days (entire period), 91 (Period I), 118 (Period II) and 139 days (Period III). Regarding helicopters, it is 33 days (entire period), 23 (Period I), 32 (Period II), and 55 days (Period III). Therefore, we can say that the process of accident occurrence in the air traffic services is in accordance with the Poisson process.

\subsection{Mathematical Model of Fatalities in Accidents}

The frequencies of fatalities from airplanes (large/small), small airplanes, large airplanes and helicopters for every 3 month interval are illustrated in Table 8. Fatalities exceeding 50 people are counted as 50 people. Table 9 shows the mean value, standard deviation (SD) and coefficient of variation (CV) of fatalities in 3 months, 6 months and 1 year. The results of the goodness-of-fit tests of fatality counts in 3 months, 6 months and 1 year in

Table 8. Frequency distribution of number of fatalities in aircraft and helicopters.

\begin{tabular}{|c|c|c|c|c|}
\hline \multirow{2}{*}{ Number of fatalities } & \multicolumn{3}{|c|}{ Aircraft } & \multirow{2}{*}{ Helicopters } \\
\hline & Total & Small & Large & \\
\hline 0 & 78 & 87 & 128 & 83 \\
\hline 1 & 18 & 15 & 12 & 25 \\
\hline 2 & 17 & 17 & 4 & 12 \\
\hline 3 & 15 & 13 & 1 & 10 \\
\hline 4 & 5 & 3 & 0 & 5 \\
\hline 5 & 3 & 4 & 0 & 3 \\
\hline 6 & 3 & 4 & 0 & 6 \\
\hline 7 & 1 & 1 & 0 & 1 \\
\hline 8 & 2 & 2 & 0 & 0 \\
\hline 9 & 2 & 2 & 0 & 0 \\
\hline 10 & 1 & 0 & 0 & 0 \\
\hline 14 & 0 & 0 & 0 & 1 \\
\hline 17 & 0 & 0 & 0 & 1 \\
\hline 20 & 0 & 0 & 0 & 1 \\
\hline 24 & 0 & 0 & 1 & 0 \\
\hline 29 & 1 & 0 & 0 & 0 \\
\hline More than 50 & 2 & 0 & 2 & 0 \\
\hline Total & 148 & 148 & 148 & 148 \\
\hline
\end{tabular}


Table 9. Mean values and standard deviations in individual periods.

\begin{tabular}{ccccccccc}
\hline Types of aircraft & Period & \multicolumn{2}{c}{ Mean value } & \multicolumn{3}{c}{ SD } & \multicolumn{2}{c}{ CV } \\
& 3 months & 2.2 & $(6.9)$ & 6.4 & $(47.8)$ & 2.87 & $(6.96)$ \\
All (large/small) & 6 months & 4.4 & $(13.7)$ & 8.8 & $(67.3)$ & 1.98 & $(4.90)$ \\
& 1 year & 8.8 & $(27.5)$ & 11.8 & $(94.3)$ & 1.34 & $(3.44)$ \\
& 3 months & 1.3 & $(1.3)$ & 2.0 & $(2.0)$ & 1.62 & $(1.62)$ \\
Small airplanes & 6 months & 2.5 & $(2.5)$ & 2.9 & $(2.9)$ & 1.15 & $(1.15)$ \\
& 1 year & 5.0 & $(5.0)$ & 4.4 & $(4.4)$ & 0.87 & $(0.87)$ \\
Large airplanes & 3 months & 1.0 & $(5.6)$ & 6.1 & $(47.8)$ & 6.14 & $(8.52)$ \\
& 6 months & 2.0 & $(11.2)$ & 8.5 & $(67.4)$ & 4.30 & $(6.00)$ \\
Helicopters & 1 year & 4.0 & $(22.5)$ & 12.0 & $(94.6)$ & 3.01 & $(4.21)$ \\
& 3 months & 1.4 & $(1.4)$ & 2.8 & $(2.8)$ & 2.01 & $(2.01)$ \\
& 6 months & 2.8 & $(2.8)$ & 4.2 & $(4.2)$ & 1.48 & $(1.48)$ \\
\hline
\end{tabular}

Values in parentheses are the calculated result based on original data, SD: Standard deviation; CV: Coefficient of Variation.

terms of individual distributions (beta, exponential, gamma, lognormal, negative binominal, normal and Poisson) are provided, utilizing "Statistically Fit Software version 2" provided by Green Mountain Software. The results of the goodness of fit of these distributions are indicated in Table 10, and the estimated values of the parameters are shown in Table 11. As shown in Table 10, the highest degree of the goodness of fit was observed in the negative binominal distribution. Regarding all airplanes (small and large), fatality distributions in 6 months and 1 year were not rejected in a chi-squared test. The 6-month distribution had the highest degree of the goodness of fit. Further, none of the fatality distributions in 6 months and 1 year regarding small airplanes and helicopters were rejected in a chi-squared test, in which the highest degree of the goodness of fit was observed. Fatality distributions regarding large airplanes were rejected in a chi-squared test. The probability density function of the negative binominal distribution is expressed as follows:

$$
P(x)=\frac{(k+x-1) !}{x !} p^{k}(1-p)^{x}
$$

In the above Formula (5) $P(x)$ represents the probability when there are deaths of $x$ people within a certain period of time, and $k$ is a constant. The negative binominal distribution demonstrates the probability distribution when there are $x$ failures before succeeding $k$ times. For instance, in Table 11, we have $k=1$ and $p=0.310$ in airplanes (large and small), which means that when there are 0 fatalities, the probability is 0.31 . Similarly, we get $k=3$ and $p=0.375$ in small airplanes, which means that when there are 0,1 or 2 fatalities, the probability is 0.375 . In other words, when there is only a minor degree of variation in fatalities and the mean value is large, there is a high probability of fatalities in that time period, which means there is a low probability of 0 fatalities when $k=1$. Therefore, in the negative binominal distribution in Table 11, as the time period for the fatality count increases, i.e., 3 months, 6 months, and 1 year, the $p$ value becomes smaller.

In the goodness-of-fit test in Table 10, the value for 1 year of large airplanes in the negative binominal distribution, and those for 1 year of airplanes (large and small) and 6 months and 1 year of large airplanes in the Poisson distribution were "not available". This result is due to the insufficient number of samples in some time periods. Regarding the occurrence intervals of air traffic accidents, the highest degree of the goodness of fit was observed in the exponential distribution. Further, we can say that the number of fatalities from air traffic accidents for a certain period of time is in accordance with the negative binominal distribution. 
Table 10. Results of the goodness of fit tests (1974-2010).

\begin{tabular}{|c|c|c|c|c|c|c|c|c|}
\hline \multirow{2}{*}{ Type of aircraft } & \multirow{2}{*}{ Period } & \multicolumn{7}{|c|}{ Probability distribution } \\
\hline & & Beta & Exponential & Gamma & Lognormal & $\begin{array}{l}\text { Negative binominal } \\
\text { distribution }\end{array}$ & Normal & Poisson \\
\hline \multirow{3}{*}{$\begin{array}{c}\text { Airplane } \\
\text { (large/small) }\end{array}$} & 3 months & 655 & 663 & 663 & 656 & 33.6 & 655 & 273 \\
\hline & 6 months & 58.6 & 64.2 & 62.9 & 64.2 & 11.7 & 122 & 77.2 \\
\hline & 1 year & 7.84 & 12 & 5.95 & 7.08 & 7.17 & 25.6 & N.A. \\
\hline \multirow{3}{*}{ Small airplane } & 3 months & 360 & 395 & 395 & 519 & 19.5 & 369 & 86.7 \\
\hline & 6 months & 74.7 & 30.1 & 30.1 & 74.7 & 4.78 & 50.7 & 13.8 \\
\hline & 1 year & 9.62 & 2.32 & 9.62 & 9.62 & 2.05 & 7.19 & 18.9 \\
\hline \multirow{3}{*}{ Large airplane } & 3 months & 1980 & 1980 & 1980 & 1980 & 78.3 & $1.98 \mathrm{E}+03$ & 155 \\
\hline & 6 months & 480 & 481 & 481 & 481 & 56.6 & 674 & N.A. \\
\hline & 1 year & 63.5 & 63.5 & 63.5 & 63.5 & N.A. & 129 & N.A. \\
\hline \multirow{3}{*}{ Helicopter } & 3 month & 542 & 562 & 562 & 544 & 14.8 & 545 & 89.6 \\
\hline & 6 month & 54.1 & 61.9 & 61.9 & 132 & 2.16 & 59.5 & 25.7 \\
\hline & 1 year & 7.84 & 15 & 5.95 & 11.6 & 1.88 & 18.8 & 15.9 \\
\hline
\end{tabular}

N.A.: not available. Values are results of a chi-squared test. Shaded Values are the results of the higher degree of goodness of fit. Those with an underline were not rejected in individual tests.

Table 11. Parameters of individual models.

\begin{tabular}{|c|c|c|c|c|c|c|c|c|c|c|c|c|c|}
\hline \multirow{3}{*}{$\begin{array}{l}\text { Type of } \\
\text { aircraft }\end{array}$} & \multirow{3}{*}{ Period } & \multicolumn{12}{|c|}{ Probability distribution } \\
\hline & & \multicolumn{2}{|r|}{ Beta } & \multirow{2}{*}{$\begin{array}{l}\text { Exponential } \\
\text { Beta }(1 / \lambda)\end{array}$} & \multicolumn{2}{|c|}{ Gamma } & \multicolumn{2}{|c|}{ Lognormal } & \multicolumn{2}{|c|}{$\begin{array}{c}\text { Negative } \\
\text { binominal }\end{array}$} & \multicolumn{2}{|c|}{ Normal } & \multirow{2}{*}{$\begin{array}{l}\text { Poisson } \\
\text { Lamda }\end{array}$} \\
\hline & & $p$ & $q$ & & Alpha & Beta & $\mathrm{Mu}(\mu)$ & Sigma $(\sigma)$ & $k$ & $p$ & Mean & Sigma & \\
\hline \multirow{3}{*}{$\begin{array}{c}\text { Airplane } \\
\text { (large/small) }\end{array}$} & 3 months & 1.1 & 31188.0 & 2.2 & 1.0 & 2.2 & 1.0 & 0.9 & 1 & 0.310 & 2.2 & 6.4 & 2.2 \\
\hline & 6 months & 1.0 & 144431.0 & 4.4 & 1.7 & 2.7 & 1.2 & 0.9 & 1 & 0.184 & 4.4 & 8.8 & 4.4 \\
\hline & 1 year & 1.2 & 21278.6 & 8.8 & 1.6 & 5.7 & 1.8 & 0.9 & 1 & 0.102 & 8.8 & 11.7 & 8.8 \\
\hline \multirow{3}{*}{ Small airplane } & 3 months & 2.3 & 1391.2 & 1.3 & 1.0 & 1.3 & 0.9 & 0.7 & 1 & 0.444 & 1.3 & 2.0 & 1.3 \\
\hline & 6 months & 1.9 & 215.1 & 2.5 & 1.0 & 2.5 & 1.0 & 0.7 & 1 & 0.286 & 2.5 & 2.9 & 2.5 \\
\hline & 1 year & 1.9 & 45.6 & 5.0 & 3.4 & 1.5 & 1.5 & 0.8 & 3 & 0.375 & 5.0 & 4.3 & 5.0 \\
\hline \multirow{3}{*}{ Large airplane } & 3 months & 0.3 & 1.2 & 1.0 & 1.0 & 1.0 & 0.7 & 1.3 & 1 & 0.502 & 1.0 & 6.1 & 1.0 \\
\hline & 6 months & 0.3 & 1.2 & 2.0 & 1.0 & 2.0 & 0.8 & 1.3 & 1 & 0.335 & 2.0 & 8.5 & 2.0 \\
\hline & 1 year & 0.7 & 8.8 & 4.0 & 1.4 & 2.9 & 1.0 & 1.4 & 1 & 0.201 & 4.0 & 11.8 & 4.0 \\
\hline \multirow{3}{*}{ Helicopter } & 3 months & 1.5 & 2558.0 & 1.4 & 1.0 & 1.4 & 0.8 & 0.8 & 1 & 0.416 & 1.4 & 2.8 & 1.4 \\
\hline & 6 months & 1.5 & 739.0 & 2.8 & 1.0 & 2.8 & 1.1 & 0.8 & 1 & 0.262 & 2.8 & 4.1 & 2.8 \\
\hline & 1 year & 1.8 & 68579.0 & 5.6 & 2.5 & 2.3 & 1.5 & 0.7 & 2 & 0.262 & 5.6 & 5.7 & 5.6 \\
\hline
\end{tabular}

\section{Summary and Conclusions}

We attempted to investigate the past trend of accidents occurring in Japan for major air traffic services such as small and large airplanes and helicopters, respectively, and countermeasures taken to prevent aircraft accidents. Utilizing statistical data, we also conducted a mathematical modeling analysis. The findings we obtained were as 
follows.

1) Accident prevention measures have been advanced in all three types of air traffic services, i.e., small airplanes, large airplanes and helicopters, contributing greatly to the decreased number of accidents. Especially, accidents mainly due to the pilot error show a significant decrease in small and large airplanes during takeoff and landing. On the other hand, we find that helicopter accidents occur more frequently during flight than during takeoff and landing, and the number of accidents caused by the major factor, pilot error, has also been decreasing. However, in terms of percentages of individual factors, accidents due to pilot error have increased only for helicopters. Although the decrease in the pilot error is significant, except for large airplanes, it still accounts for the highest percentage of accident factors.

2) It is clear that the number of accidents due to weather factors has not been reduced. Particularly for large airplanes, it has not been reduced at all, or rather, it has increased both in the total number and the percentage. This is an indication of the fact that measures to counter weather factors are extremely difficult to implement, which remains a major issue to be solved.

3) We found that the decrease in the number of accidents was achieved through various safety efforts made by every person involved in air traffic services, including strengthening of the rules in public policy, technological innovations in airplanes, helicopters and the surrounding facilities such as airports and air control radars, improvements in the training method for mechanics and traffic controllers and advancements in related techniques, the enhancement of public rules, and numerous measures taken by individual related companies. Further efforts to ensure the safety of old airplanes and helicopters are also necessary and required.

4) We conducted mathematical model analyses on economic growth, aviation demand, accident figures, intervals of accident occurrence, and fatalities. Results suggested that, in terms of economic growth, aviation demand and accident figures, our regression model could indicate a decrease in the accident figures together with the growing economy and aviation demand until 1991. We also found that, regarding the intervals of accident occurrence and the number of fatalities, a good fit for the probability distribution was observed for the exponential distribution and the negative binominal distribution, respectively.

As described above, we understand that small and large airplanes and helicopters have different characteristics, and therefore, it is necessary to develop separate accident prevention measures suitable for individual types of aircraft. Regarding small airplanes, as the airplane itself cannot be replaced easily, there are some accidents caused by using old airplanes. The number of accidents will not decrease even if warning tone systems for incorrect actions and the layout of the cockpit are improved in new models. Therefore, we assume that it will be effective to develop systems that will reduce the number of accidents due to the pilot error, such as a modularized warning tone system that can be installed in old models, and to make their installation mandatory.

Regarding large airplanes, the major issue is weather, for which individual airlines have been implementing various measures. The most effective way to reduce the number of large airplane accidents is to continue undertaking such measures. Regarding helicopters, there is the high possibility of accidents due to the pilot error, especially collisions, as helicopters often fly at low altitudes. We assume that it will help reduce the number of accidents through a thorough preliminary observation of the surrounding environment, enhanced pilot training, as well as the development of a warning system in which obstacles and GPS are closely linked to each other.

We consider that there may exist some other causes for aircraft accidents such as pilot's mental and psychological disorder, terrorist attacks and so on. How to deal with these troubles to prevent accidents will be the remaining and future problems. It is also very important to conduct a study and systematization from the viewpoint of how to survive an accident, to mitigate injury and to reduce the number of injuries.

\section{References}

[1] Bazargan, M. and Vitaly, S.G. (2011) Impact of Gender, Age and Experience of Pilots on General Aviation Accidents. Accident Analysis \& Prevention, 43, 962-970. http://dx.doi.org/10.1016/j.aap.2010.11.023

[2] Chang, Y.-H. and Yang, H.-H. (2010) Aviation Occupant Survival Factors: An Empirical Study of the SQ006 Accident. Accident Analysis \& Prevention, 42, 695-703. http://dx.doi.org/10.1016/j.aap.2009.10.018

[3] Rinoie, K. (2008) Aviation Safety from Viewpoint of Aircraft Design and Operation. Journal of Reliability Engineering Association of Japan, 30, 362-368.

[4] Shiroyama, H., Murayama, A. and Kajimura, I. (2003) Legal System for Safety Concerning Aircraft Accidents in the United States: Suggestions for Japan. Journal of the Sociotechnology Research Network, 1, 149-158. 
[5] Nakasuga, S. (1995) A Study on Human Factors in Aircraft and Enhanced Safety. Journal of Reliability Engineering Association of Japan, 17, 12-21.

[6] Kamiyama, T. (1976) Safety and Reliability of Aircraft. Operations Research Society of Japan, 21, 424-431.

[7] The Japan Transport Safety Board, Transport Ministry’s Aircraft Accident Investigation Commission, Aircraft Accidents Report. http://jtsb.mlit.go.jp/jtsb/aircraft/index.php

[8] Aviation Statistics Catalogue, Japan Aeronautic Association, 1984-85, 1998-99, 2001, 2011.

[9] Rodrigues, C.C. and Cusick, S.K. (2012) Commercial Aviation Safety. McGraw Hill, New York.

[10] Sugie, H. (2010) Professional Pilot. IKAROS Publications, Tokyo.

[11] Yanagida, K. (2010) Longing for Air Safety. 100 Years of Japanese Aviation. Japan Aeronautic Association.

[12] Tsumajika, E. (2010) Japan's Sky Returned to Japan after the War. 100 Years of Japanese Aviation. Japan Aeronautic Association.

[13] Shimada, H. (2011) 50 World Classic Passenger Aircraft. SB Creative, Tokyo.

[14] Yamamoto, T. (2010) Policy for the Development of Air Transport Businesses. 100 Years of Japanese Aviation. Japan Aeronautic Association.

[15] Masui, K. and Takahashi, H. (1987) Shift in Public Transport Policy. Nippon Hyoron Sha Co., Ltd., Tokyo.

[16] Tazaki, T. (2010) Shizukuishi Accident and Restructuring of the Aviation Security System. 100 Years of Japanese Aviation. Japan Aeronautic Association.

[17] Ministry of Internal Affairs and Communications Statistics Bureau, Japan Statistical Yearbook, 1981, 1985, 1989, 1993/94, 1997, 2002, 2007, 2010, 2014, Japan Statistical Association. 